\title{
Preços de commodities e nível de atividade em uma pequena economia aberta: evidências empíricas para o estado do Espírito Santo ${ }^{1}$
}

\author{
Matheus Albergaria de Magalhães ${ }^{2}$
}

\section{Resumo}

O presente trabalho propõe-se a mensurar, empiricamente, os efeitos de variações nos preços de commodities sobre o nível de atividade do estado do Espírito Santo ao longo do tempo, assim como a comparar os impactos desses preços sobre a economia estadual vis-à-vis à economia nacional e demais estados brasileiros. Os resultados obtidos permitem identificar cinco padrões empíricos distintos: (i) por conta de seu alto grau de abertura, o estado do Espírito Santo sente mais intensamente os impactos de choques nos preços de commodities do que o Brasil e outros estados; (ii) resultados de testes de Granger-causalidade demonstram que preços de commodities exercem um padrão de precedência temporal sobre os níveis de atividade estadual e nacional; (iii) padrão semelhante de precedência temporal também ocorre no caso de amplo conjunto de variáveis econômicas relacionadas ao estado do Espírito Santo; (iv) um choque positivo nos preços de commodities faz com que o nível de atividade estadual aumente inicialmente, sofrendo uma contração em seguida, para então apresentar um aumento permanente em relação a seu nível original no longo prazo; (v) resultados de um exercício de decomposição da variância demonstram que, em média, os impactos quantitativos de choques nos preços de commodities são maiores no caso estadual do que no caso nacional. Esses resultados são robustos a diversas questões de especificação, como o uso de diferentes transformações estacionárias dos dados e de distintos números de defasagens empregados em testes de Granger-causalidade. São importantes no sentido de gerarem melhor compreensão dos efeitos de oscilações nos preços de commodities sobre uma pequena economia aberta, conforme parece ser o caso do Espírito Santo.

Palavras-chave: Macroeconomia aberta; Commodities; Espírito Santo.

\section{Abstract \\ Commodity prices and activity level in a small open economy: empirical evidence for the State of Espírito Santo}

This paper aims to measure the effects of commodity price variations on output fluctuations over time in the State of Espírito Santo. The impacts of these prices on the State's economy compared to the national economy and other Brazilian states will also be measured. The results obtained reveal

(1) Trabalho recebido em 10 de março de 2010 e aprovado em 05 de novembro de 2011. Equivale a uma versão substancialmente revisada de Magalhães (2010).

(2) Especialista em Pesquisas Governamentais do Instituto Jones dos Santos Neves (IJSN), Vitória, ES, Brasil. E-mail: matheus@ijsn.es.gov.br. O autor agradece os comentários e sugestões de Ana Paula Vescovi, Sávio Caçador, Victor Toscano e dos participantes de seminários ocorridos no Instituto Jones dos Santos Neves (IJSN) e na Universidade Federal do Espírito Santo (UFES). As estagiárias Jessica Rangel e Manoela Andrade providenciaram excelente assistência de pesquisa. Vale a ressalva de que as opiniões aqui contidas não refletem as opiniões do IJSN ou de algum outro membro dessa Instituição. Também, vale a ressalva usual de que os erros e idiossincrasias remanescentes devem-se única e exclusivamente ao autor. 
five distinct empirical patterns: (i) given the state's high degree of openness, the impacts of commodity price fluctuations tend to be stronger when compared to Brazil and other Brazilian States; (ii) Granger-causality test results show that commodity prices precede output levels both in the case of the State and the country; (iii) a similar result occurs when a broad set of economic variables related to the State of Espírito Santo are considered; (iv) a positive shock to commodity prices causes output to initially rise, followed by a contraction, with this variable displaying a permanently higher level in the long run; (v) variance decomposition results show that, on average, the quantitative impacts of commodity price shocks are larger in the case of the State than the country. The results obtained are robust with regards to several specification issues, such as different stationary transformations of data, as well as distinct number of lags employed in Granger-causality tests. These results are important in the sense of providing a better understanding of the effects of commodity price variations on a small, open economy, as seems to be the case for the State of Espírito Santo.

Keywords: Open-economy macroeconomics; Commodities; Espírito Santo.

JEL C22, F41, R11.

\section{Introdução}

O Espírito Santo possui um alto grau de abertura ao comércio exterior. Estimativas do coeficiente de abertura do estado apontam para uma magnitude em torno de 50\% (Magalhães; Toscano, 2009; Pereira; Maciel, 2010). Significa que, a cada R\$ 100 produzidos em território estadual, cerca de R\$ 50 são destinados ao setor externo. Esse fato acaba fazendo com que a economia local fique extremamente condicionada a acontecimentos ocorridos no cenário internacional.

Em particular, por ser a pauta de exportações do Espírito Santo concentrada em commodities, nota-se que variações nos preços desses bens acabam tendo um impacto pronunciado na economia ${ }^{3}$. Assim, o objetivo do presente trabalho equivale a quantificar os efeitos de variações nos preços de commodities sobre o nível de atividade estadual. Adicionalmente, busca-se averiguar a ocorrência de eventuais diferenças das respostas do estado em comparação a outras Unidades da Federação (UFs) ${ }^{4}$.

A importância do tema reside no fato de que, dada a estrutura produtiva local da economia espírito-santense, o presente trabalho pode ser visto como uma

(3) O termo "commodities" serve para designar bens em estado bruto ou com pequeno grau de industrialização, de qualidade quase uniforme, produzidos em grande quantidade e por diferentes produtores. Basicamente, commodities equivalem a produtos padronizados, cujo preço não é definido pelo produtor, o que faz com que sua estrutura de produção possa ser razoavelmente aproximada a partir de um mercado competitivo (em concorrência perfeita). Segundo Puga (2008, p. 2): “A definição de commodities não é pacífica. A princípio, engloba os produtos intensivos em recursos naturais, padronizados e com tecnologia de produção amplamente conhecida, sendo o termo geralmente associado a bens negociados em Bolsa de Mercadorias. Essa lista, no entanto, costuma ser acrescida por bens como minério de ferro, aço e alimentos industrializados que, embora não sejam padronizados e nem negociados em Bolsa, guardam semelhança com as commodities nos demais aspectos" (Grifos do autor).

(4) Breves análises relacionadas à importância das commodities no comércio exterior brasileiro estão contidas em Puga (2008) e Pereira (2009). 
análise empírica dos efeitos de preços de commodities sobre uma pequena economia aberta. Ademais, alguns dos resultados obtidos, relacionados ao padrão de precedência temporal desses preços sobre a produção local, podem justificar a construção de indicadores antecedentes de nível de atividade com base em commodities.

Para se quantificar os efeitos dos preços de commodities sobre o nível de atividade, serão empregadas neste artigo técnicas econométricas referentes a séries temporais. Especificamente, será baseado em modelos de vetores autorregressivos (VARs), assim como testes de Granger-causalidade, com ambas as técnicas sendo amplamente usadas na área de Macroeconomia aplicada ${ }^{5}$.

O trabalho está dividido da seguinte maneira: na primeira seção, é feita uma breve revisão de alguns dos trabalhos relacionados ao tema; a segunda seção apresenta uma caracterização do comércio exterior do estado do Espírito Santo. A terceira descreve a base de dados empregada; a quarta contém os principais resultados da análise empírica conduzida. A quinta seção, por sua vez, contém testes de robustez relacionados a alguns dos principais resultados empíricos obtidos. A última apresenta as principais conclusões do trabalho e fornece algumas sugestões de pesquisa futura sobre o tema.

\section{Referencial teórico}

Prates (2007) equivale a uma referência pioneira em termos de literatura nacional sobre a importância dos preços de commodities na economia. No caso, a autora busca explicar a tendência de alta dos preços desses bens ocorrida a partir do ano de 2001. Para tanto, elabora uma detalhada análise da evolução dos preços de distintos tipos de commodities (alimentícias, metálicas e agrícolas), concluindo que, em geral, tais preços apresentam um padrão nitidamente procíclico (i.e., aumentam quando aumenta o produto agregado e vice-versa). A autora também conclui que os preços de commodities metálicas exibem maior correlação com o nível de atividade industrial, uma vez que a oferta desses bens tende a reagir de forma mais lenta a aumentos de demanda em comparação a commodities agrícolas, o que faz com que o mercado para esse tipo de commodity assemelhe-se mais ao mercado de petróleo do que ao de matérias-primas agrícolas.

A autora finaliza seu estudo, sugerindo que a alta de preços de commodities ocorrida no período 2002/2005 esteve associada a uma sobreposição de fatores: recuperação econômica global, desvalorização do dólar, bolhas especulativas fomentadas por baixas taxas de juros e devido ao marcante crescimento econômico da China, registrado ao longo desse período. Embora reconheça a dificuldade de se isolar alguns desses fatores como principais

(5) Para maiores informações a respeito dessas técnicas, ver, a título de exemplo, Canova (1995); Enders (1995, cap. 5); Stock e Watson (2001). As referências seminais sobre esses temas equivalem aos trabalhos de Granger (1969) e Sims (1980). 
determinantes da trajetória de alta dos preços de commodities, a autora levanta duas hipóteses básicas a respeito: a crescente importância da economia chinesa em termos globais ("efeito-China") e as condições macroeconômicas internas vigentes ao longo do período de análise.

Por sua vez, o estudo empírico de Prates e Marçal (2008) equivale a uma tentativa de mensuração do desempenho exportador brasileiro ao longo do período 1999/2006, levando em conta a influência da tendência de alta dos preços de commodities para esse desempenho. Segundo os autores, entre os anos 2003 e 2006, a pauta brasileira de exportações esteve concentrada, principalmente, em commodities primárias e bens de baixa intensidade tecnológica. O Brasil, assim, acabou sendo beneficiado no contexto internacional da época, não apenas por conta do aumento dos preços de commodities, mas também de características específicas da expansão econômica da China no período e da recuperação sincronizada da economia mundial. O resultado final desse processo foi a ocorrência de um aumento de participação de mercado do Brasil nas importações mundiais.

Utilizando técnicas de cointegração, os autores buscam quantificar a importância do aumento dos preços de commodities sobre o desempenho observado das exportações brasileiras ao longo do período de análise. Os resultados obtidos demonstram que o padrão de alta observado foi, de fato, um significativo determinante do desempenho favorável das exportações nacionais no período, tanto por causa de seus impactos diretos ("efeito-preço") quanto indiretos ("efeito-quantidade").

Baseando-se em dados históricos correspondentes a um período de aproximadamente 300 anos, Jacks, O'Rourke e Williamson (2009) buscam responder a diversas questões relacionadas a padrões empíricos de preços de commodities. Para tanto, os autores partem da constatação de que países pobres tendem a apresentar maior volatilidade em suas flutuações econômicas devido ao fato de terem uma pauta de exportações concentrada em um número relativamente reduzido de produtos básicos ${ }^{6}$.

Adicionalmente, esses autores ressaltam que a ocorrência de um excesso de volatilidade no nível de atividade pode ser prejudicial ao crescimento de longo prazo de uma nação. Os resultados obtidos a partir da análise dos dados históricos considerados permitem a identificação dos seguintes padrões empíricos: (i) não houve aumento na volatilidade de preços de commodities desde o ano de 1700; (ii) os preços de commodities sempre exibiram maior volatilidade do que os preços de bens manufaturados; (iii) processos de integração econômica tendem a reduzir a volatilidade dos preços de commodities.

(6) Como colocam os autores: “(...) Primary products, or export commodities as they are often called, experience far greater price volatility than do manufactures or services, although this is more often assumed than demonstrated in the literature (...)" (Jacks; O'Rourke; Williamson, 2009, p. 3-4). 
Em particular, os autores obtêm uma conclusão que vai contra a hipótese de Prebisch (1950) de que os preços de commodities exibiriam um padrão mais volátil do que os preços de bens industrializados, uma vez que os últimos teriam suas flutuações reduzidas devido ao surgimento da moderna indústria corporativa. Segundo Jacks, O'Rourke e Williamson (2009), se essa hipótese fosse de fato apoiada pelos dados, então diferenças de volatilidade nos preços dessas duas categorias de bens deveriam ter surgido apenas a partir do final do século XIX. A evidência empírica reportada pelos autores não indica, entretanto, a ocorrência dessa diferença no período supracitado, com preços de commodities apresentando um padrão mais volátil do que preços de bens industrializados ao longo dos últimos 300 anos e não apenas a partir da década de 1950, conforme a hipótese de Prebisch (1950).

Baseando-se nas referências citadas anteriormente o presente trabalho buscará evidenciar alguns padrões empíricos relacionados a preços de commodities, com ênfase em seus impactos sobre o nível de atividade do estado do Espírito Santo.

\section{Caracterização do comércio exterior do estado do Espírito Santo ${ }^{7}$}

Conforme dito acima, o Espírito Santo pode ser caracterizado como um dos estados com maior coeficiente de abertura do país. Distintos estudos destinados a mensurar o grau de abertura do estado chegaram à mesma conclusão em termos de sua posição frente a outras UFs, embora possam haver diferenças em termos de magnitudes do coeficiente de abertura propriamente dito, decorrentes de diferenças em termos de períodos de análise e/ou metodologias empregadas. A Tabela 1 resume alguns dos estudos relacionados ao tema.

Tabela 1

Estimativas de Grau de Abertura (G.A.) para o estado do Espírito Santo

de acordo com distintos estudos empíricos

\begin{tabular}{l|c|c|c|c}
\hline \multicolumn{1}{c|}{ Autores } & Período Amostral & $\begin{array}{c}\text { Frequência } \\
\text { Temporal }\end{array}$ & Estimativa G.A. & $\begin{array}{c}\text { Posição } \\
\text { Ranking }\end{array}$ \\
\hline Souza (2003) & $1991 / 2000$ & Anual & $60,8 \%$ & $1^{\text {o }}$ \\
\hline Magalhães e Toscano (2009) & $2004: 01 / 2009: 02$ & Trimestral & $48,7 \%$ & n.c. $^{\text {a }}$ \\
\hline Pereira e Maciel (2010) & $2000 / 2006$ & Anual & $50,3 \%$ & $1^{\text {o }}$ \\
\hline
\end{tabular}

Nota: (a) O termo "n.c." denota "nada consta". No caso do artigo de Magalhães e Toscano (2009), os autores não elaboraram um ranking de coeficientes de abertura das UFs, uma vez que trabalham apenas com dados referentes ao estado do Espírito Santo e Brasil.

Fontes: Souza (2003); Magalhães e Toscano (2009); Pereira e Maciel (2010).

(7) Para maiores informações a respeito da evolução econômica do estado do Espírito Santo durante o ano de 2009, ver Panorama Econômico (2009). O estudo de Magalhães e Toscano (2010) corresponde a uma análise dos efeitos da crise de 2007-2008 sobre o comércio exterior desse estado ao longo do mesmo período. 
Magalhães e Toscano (2009) calcularam estimativas trimestrais do coeficiente de abertura do Espírito Santo, comparando essas estimativas com o caso brasileiro. O Gráfico 1 contém a evolução temporal dessas duas variáveis ao longo do período 2004:01/2009:02.

\section{Gráfico 1}

Estimativas de Grau de Abertura (G.A.) para o estado do Espírito Santo, 2004:01/2009:02 (dados trimestrais)

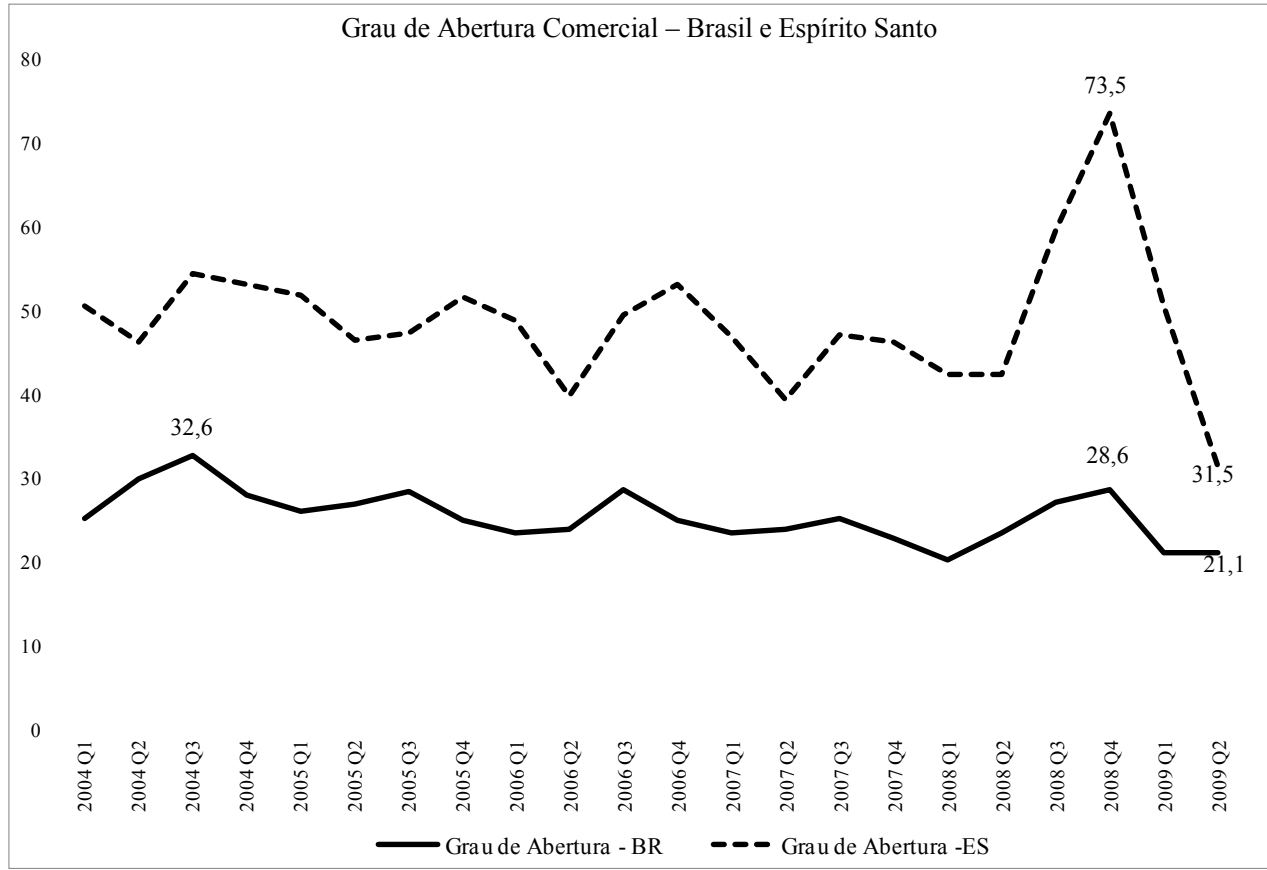

Fonte: Magalhães e Toscano (2009, Gráfico 2, p. 1).

De acordo com os resultados contidos nesse gráfico, pode-se notar que o Espírito Santo apresentou um coeficiente de abertura nitidamente superior ao caso nacional ao longo de todo o período amostral analisado. Adicionalmente, nota-se que as estimativas supracitadas registraram alguma variação ao longo do tempo, com as medidas de grau de abertura estadual e nacional, tendo sofrido uma contração no período 2007-2008, por conta dos efeitos da crise financeira internacional, originada no mercado imobiliário norte-americano, o que acabou ocasionando uma redução simultânea de exportações e importações estaduais.

Em termos de pauta de exportações, o Espírito Santo pode ser caracterizado, principalmente, como um estado exportador de bens básicos e 
intermediários $^{8}$. A Tabela 2 contém dados que corroboram essa última afirmação, uma vez que apresenta as participações percentuais dos bens exportados e importados pelo estado no ano de 2009, classificados por fator agregado.

Tabela 2

Participações percentuais de bens (Classificação por fator agregado) nas exportações e importações do estado do Espírito Santo, 2009

\begin{tabular}{|c|c|c|}
\hline \multicolumn{3}{|c|}{ Participação (\%) } \\
\hline & Exportações & Importações \\
\hline Básicos & 47,29 & 5,49 \\
\hline Manufaturados & 21,94 & 88,87 \\
\hline Semimanufaturados & 28,23 & 5,65 \\
\hline Consumo de Bordo & 2,54 & - \\
\hline \multicolumn{3}{|c|}{$\begin{array}{l}\text { Nota: O termo "Consumo de Bordo" serve para denotar o conjunto de bens } \\
\text { transacionados entre residentes e não residentes a bordo de aeronaves, } \\
\text { embarcações etc. (Disponível em: http://www.bcb.gov.br/ftp/infecon/BalPagSet_P.pdf. } \\
\text { Acesso em: } 15 \text { mar. 2010). } \\
\text { Fonte: Magalhães e Toscano (2010, Tabela 2, p.7). }\end{array}$} \\
\hline
\end{tabular}

Os dados da última tabela demonstram que cerca de metade das exportações do estado $(47,3 \%)$ equivalem a produtos básicos, enquanto que, em termos de importações, a ampla maioria (89\%) dos bens transacionados corresponde a bens manufaturados.

Por outro lado, o Gráfico 2 contém a composição das exportações e importações estaduais em 2009, assim como os respectivos percentuais correspondentes a cada tipo de bem. A diferença em relação à tabela anterior diz respeito à classificação de bens utilizada. Especificamente, no caso desse gráfico, fez-se uso da classificação por categoria de uso, ao passo que no caso da última tabela foi utilizada a classificação por fator agregado.

Conforme é possível notar a partir da inspeção do gráfico, o estado do Espírito Santo possui uma pauta de importações mais diversificada do que a de exportações. Especificamente, o estado importa bens de consumo, de capital e intermediários, ao mesmo tempo em que possui a vasta maioria de suas exportações $(97 \%)$ concentrada em bens intermediários.

(8) Especificamente, ocorre uma situação em que um número relativamente reduzido de bens (cinco) responde por mais de $80 \%$ dos valores exportados pelo estado. Para maiores detalhes a esse respeito, ver Magalhães e Toscano (2011). 
Gráfico 2

Participações percentuais de bens (Classificação por categoria de uso) nas exportações e importações do estado do Espírito Santo, 2009

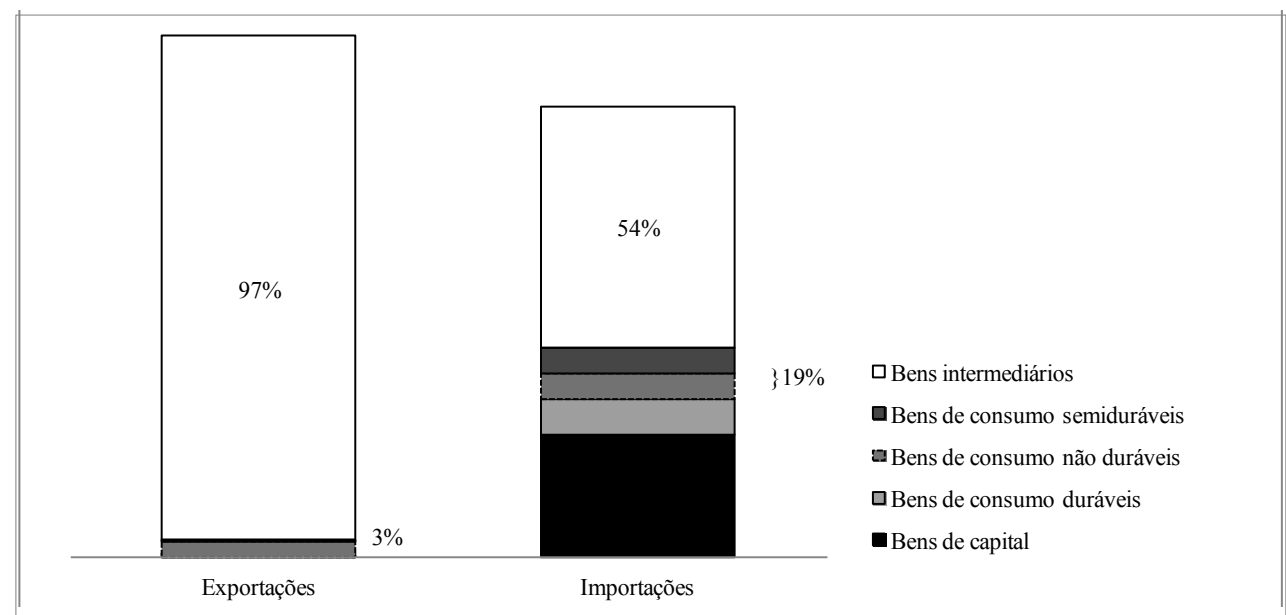

Fonte: Magalhães e Toscano (2010, Gráfico 8, p.15).

Por conta de seu alto grau de abertura e por ter uma pauta de exportações concentrada na produção de um número relativamente pequeno de bens básicos $\mathrm{e}$ intermediários, o estado do Espírito Santo apresenta, em geral, um maior grau de volatilidade em suas flutuações econômicas em comparação ao Brasil e demais UFs. O Gráfico 3 descreve a evolução dos componentes cíclicos (obtidos via filtro Hodrick-Prescott ${ }^{9}$ ) das séries de produção industrial do Brasil e do Espírito Santo ao longo do período 1991:01/2009:02 (dados trimestrais). Adicionalmente, esse gráfico expõe as recessões ocorridas no país ao longo do período em análise, de acordo com a cronologia criada pelo Comitê de Datação dos Ciclos Econômicos (Codace) e correspondentes às áreas em cinza do gráfico (Conjuntura Econômica 2009).

O padrão gráfico reportado permite inferir dois fatos: primeiro, os ciclos das séries de produção industrial nacional e estadual apresentam um padrão contracionista ao longo da maior parte das recessões ocorridas no país, embora não haja um perfeito padrão de sincronia; segundo, nota-se uma maior volatilidade relativa dos ciclos industriais do estado, em comparação aos ciclos do país, especialmente no caso dos últimos períodos da amostra considerada ${ }^{10}$.

(9) No caso da aplicação do filtro Hodrick-Prescott às séries analisadas, foi utilizado um parâmetro de suavização $\lambda=1600$, em consonância com estudos aplicados a dados de frequência trimestral. Para maiores informações a respeito desse filtro, ver Hodrick e Prescott (1997).

(10) O desvio-padrão do componente cíclico da produção industrial do Espírito Santo ao longo do período considerado (1991:01/2009:02) foi 5,92\%, uma magnitude equivalente a 1,57 vezes o desvio-padrão do componente cíclico da produção industrial do Brasil, que foi 3,76\%. No período anterior à crise de 2008, o componente cíclico da produção industrial estadual apresentou um aumento de $+16,18 \%$, ao passo que ocorreu 


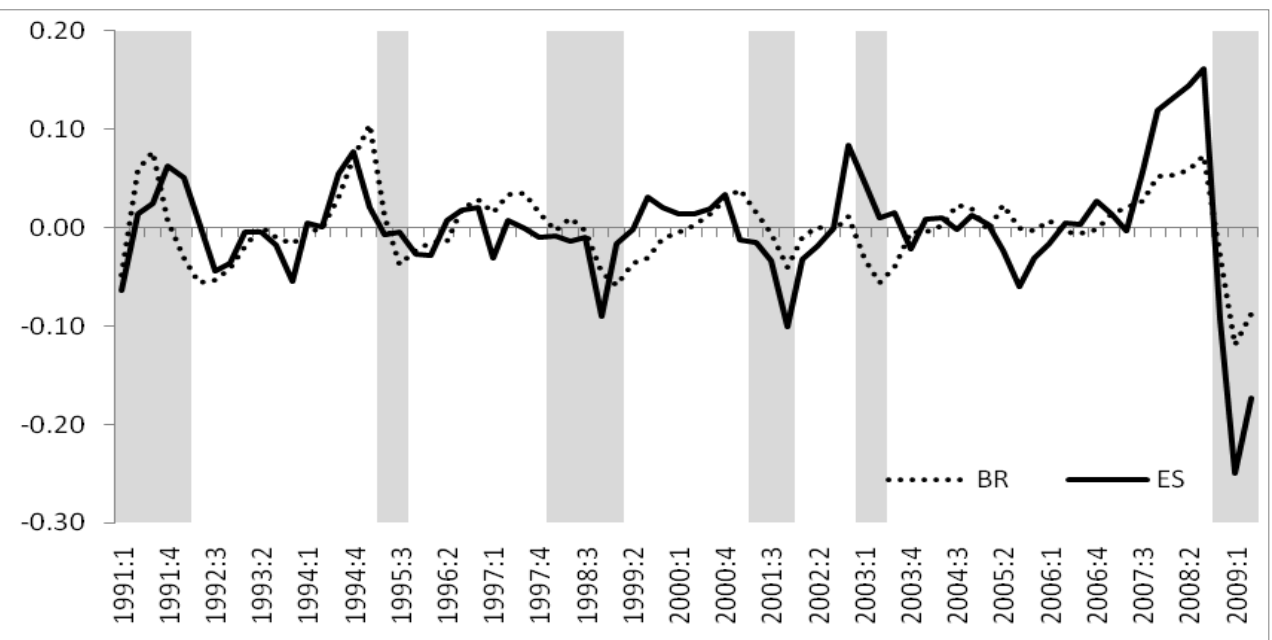

Notas: (1) Os dados utilizados no gráfico acima possuem periodicidade trimestral, englobando o período 1991:01/2009:02. Todos os dados estão em escala logarítmica, com seus componentes cíclicos obtidos a partir do filtro Hodrick-Prescott, considerando $\lambda=1600$; (2) Áreas em cinza equivalem a períodos de recessão na economia brasileira, em consonância com a cronologia desenvolvida pelo Comitê de Datação dos Ciclos Econômicos (Codace).

Fonte: Magalhães e Ribeiro (2011, Gráfico 3).

O Gráfico 4 confirma a maior volatilidade relativa da economia estadual em comparação à economia nacional no caso do uso de distintos índices de produção industrial. Nesse gráfico, estão expostos os desvios-padrão das séries temporais dos índices correspondentes às indústrias geral, extrativa e de transformação, tanto no caso do Espírito Santo (gráfico à esquerda) quanto no caso do Brasil (gráfico à direita). Para facilitar a comparação dessas séries, as escalas de ambos os gráficos foram padronizadas ${ }^{11}$. Novamente, é possível constatar a ocorrência de um padrão mais volátil no caso espírito-santense, com a indústria extrativa estadual tendo alcançado um valor máximo de 45,27\% em seu desviopadrão no primeiro trimestre de 2009 , um valor cerca de quatro vezes superior ao valor reportado para a mesma indústria no caso nacional (11,39\%).

um aumento de apenas $+7,36 \%$, no caso nacional. Por outro lado, uma vez que os efeitos adversos da crise passaram a ser sentidos no país, o Espírito Santo registrou uma queda de $-24,95 \%$, enquanto que a queda no caso brasileiro foi de apenas $-11,88 \%$. Para maiores detalhes a respeito do padrão cíclico da economia do Espírito Santo ao longo do período 1991/2009, ver Magalhães e Ribeiro (2011).

(11) Esses gráficos foram construídos a partir do cálculo de medidas de desvios-padrão em janelas móveis de quatro trimestres, em moldes semelhantes a Blanchard e Simon (2001, Figura 1, p. 138), que analisam a volatilidade do nível de atividade da economia norte-americana ao longo do período 1947/2000. 
Os resultados reportados no gráfico ressaltam um padrão comum à economia do Espírito Santo nos últimos anos: sua extrema volatilidade, com a economia estadual tendendo, em geral, a crescer acima da média nacional durante períodos de prosperidade e tendendo a contrair a níveis abaixo da média nacional durante períodos de recessão (Magalhães; Ribeiro, 2011).

Gráfico 4

Volatilidade das séries de produção industrial

Brasil e Espírito Santo, 1991:01/2009:02 (dados trimestrais)

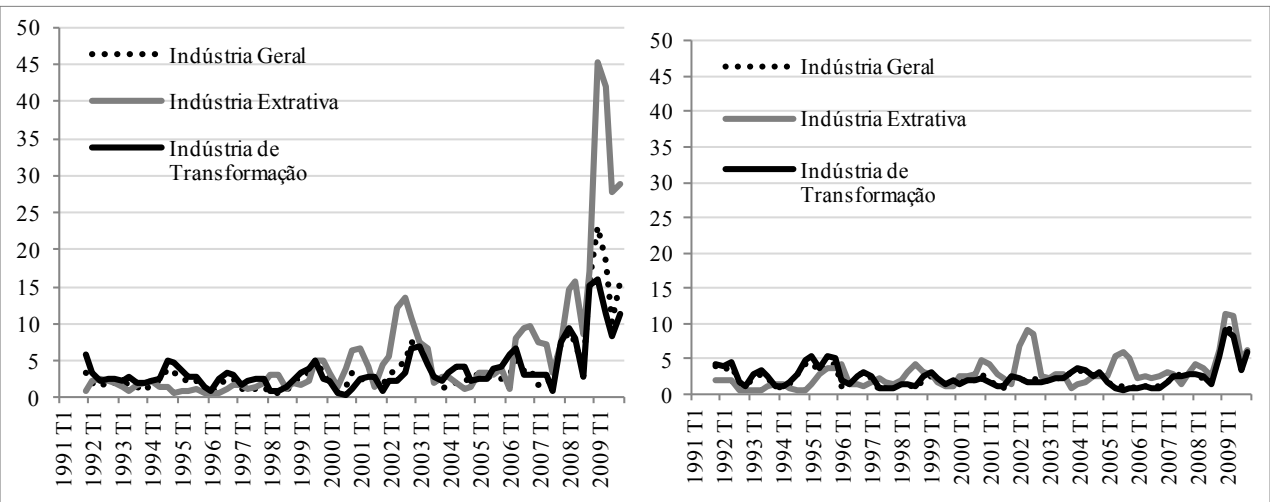

Nota: Séries expostas nos gráficos correspondem a desvios-padrão em janelas móveis de quatro trimestres, calculados a partir da metodologia descrita em Blanchard e Simon (2001).

Fonte: Magalhães e Toscano (2010, Gráfico 5, p.10).

A partir dos resultados descritos nesta seção, é possível constatar que, por conta de sua estrutura econômica, o Espírito Santo constitui um bom exemplo de pequena economia aberta, uma vez que possui uma pauta de exportações concentrada, principalmente, em bens básicos e intermediários, ao mesmo tempo em que não exerce influência sobre preços internacionais dos bens que exporta ou importa. Em termos gerais, os resultados da análise subsequente podem constituir evidência inicial acerca dos efeitos de choques macroeconômicos ocorridos no cenário internacional sobre uma pequena economia aberta.

\section{Base de dados}

No caso deste trabalho, foram utilizados dados referentes a índices de preços de commodities e níveis de atividade nacional e estadual. Especificamente, no caso dos preços de commodities, foram utilizados os índices do Commodity Research Bureau $(\mathrm{CRB}, 2010)^{12}$. Para alguns testes de robustez, também foram

(12) O CRB produz diversos indicadores relacionados a preços de commodities. O índice CRB de preços de commodities utilizado no presente trabalho é composto pelos preços de 22 commodities distintas. No caso do estado do Espírito Santo, as commodities mais importantes em termos de exportações estaduais são as seguintes: minérios de ferros aglomerados (pellets) $(37,9 \%$ de participação no total de exportações), produtos semimanufaturados de ferro e aço $(13,5 \%)$, Celulose $(12,6 \%)$, Rochas Ornamentais $(6,4 \%)$ e Café $(5,7 \%)$ 
utilizados índices provenientes do Fundo Monetário Internacional (FMI) (IMF, 2010) (maiores detalhes adiante).

Em termos de nível de atividade, foram utilizados índices de produção industrial do Brasil, do Espírito Santo e de outras UFs, cuja fonte primária é a Pesquisa Industrial Mensal - Produção Física (PIM-PF), do Instituto Brasileiro de Geografia e Estatística (IBGE) ${ }^{13}$. Especificamente, esses índices servem para representar medidas de nível de atividade das respectivas economias às quais estão associados. O período amostral analisado equivale a 1998:01/2009:03, com os dados estando em frequência trimestral, em consonância com estudos relacionados a flutuações de curto prazo da economia (ciclos de negócios) (Stock; Watson, 2000).

O Apêndice A contém uma breve descrição das séries temporais empregadas no trabalho.

\section{Resultados}

Nesta seção, são expostos os principais resultados da análise empírica conduzida no trabalho.

\subsection{Análise preliminar}

O Gráfico 5 apresenta a evolução temporal das séries de produção industrial do Brasil e do Espírito Santo ao longo do período 1998:01/2009:03 (dados trimestrais), assim como do índice CRB, com todas as variáveis expressas em escala logarítmica natural. Do mesmo modo, também são expostas no gráfico áreas correspondentes a recessões no caso brasileiro, em consonância com a classificação proposta pelo Codace.

Os padrões descritos no gráfico permitem inferir que todas as séries consideradas, quando expressas em log-níveis, apresentam trajetórias bastante semelhantes ao longo do período analisado ${ }^{14}$.

(informações obtidas a partir da Secretaria de Comércio Exterior do Ministério do Desenvolvimento, Indústria e Comércio Exterior (Secex-MDIC)). Detalhes relacionados à composição do índice CRB estão disponíveis no próprio website dessa instituição: http://www.crbtrader.com/crbindex/spot background.asp. Acesso em: 13 abr. 2010.

(13) Vale a ressalva de que existem diferenças na composição dos índices de produção industrial de acordo com a UF considerada, uma vez que o IBGE considera indústrias que representem ao menos $80 \%$ da indústria local (média do triênio 1998-2000) quando da construção desses índices. O estado do Espírito Santo, por sua vez, é composto por 5 (cinco) setores, apenas (IBGE, 2004). É provável que tais diferenças de composição possam afetar os resultados de análises envolvendo comparações entre esses indicadores. Fica a sugestão de que a pesquisa futura busque verificar as diferenças citadas a partir da elaboração de estudos utilizando microdados nos moldes sugeridos por Bartelsman e Doms (2000), por exemplo.

(14) Em princípio, o padrão gráfico das séries consideradas poderia sugerir a ocorrência de um padrão de cointegração, embora sejam necessários testes adicionais para a eventual confirmação desse diagnóstico (maiores detalhes adiante). 
Gráfico 5

Séries temporais do Índice de preços CRB e dos Índices de produção industrial nacional e estadual, 1998:01/2009:04 (dados trimestrais)

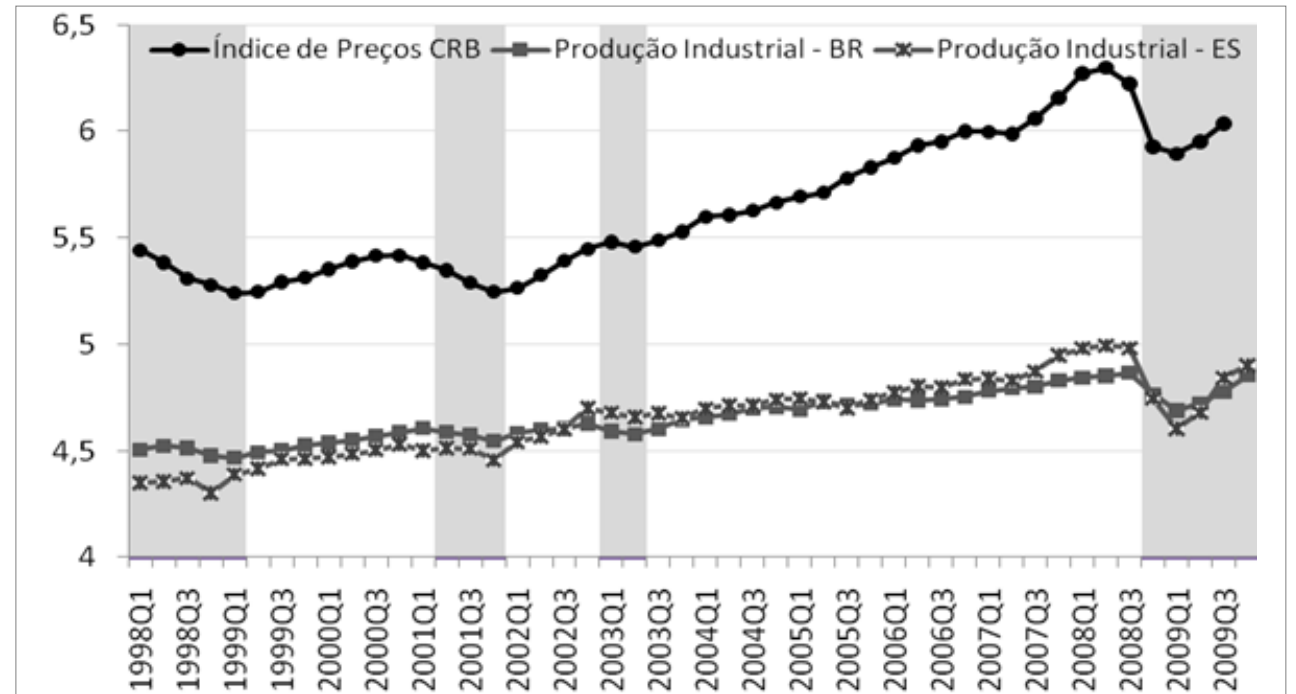

Fonte: Cálculos do autor, com base em dados do CRB e do IBGE.

Os Gráficos 6 e 7, por sua vez, apresentam a evolução temporal de transformações estacionárias das mesmas variáveis, sendo que, no primeiro gráfico, são apresentadas as primeiras diferenças dos logaritmos naturais das séries e, no segundo gráfico, os componentes cíclicos das séries, obtidos via filtro Hodrick-Prescott. O intuito básico de ambos os gráficos equivale a ressaltar as oscilações de curto prazo do índice de preços de commodities e dos índices de produção industrial analisados.

De acordo com os padrões reportados nos dois gráficos, as oscilações do índice CRB são nitidamente mais voláteis do que as dos índices de produção industrial estadual e nacional (o desvio-padrão do primeiro índice equivale a 1,4 e 2,7 vezes os desvios-padrão dos índices estadual e nacional, respectivamente, no caso dos componentes cíclicos das séries). Em especial, no caso da crise de 2008, nota-se uma queda acentuada em todas as séries analisadas, com posterior recuperação no período recente. Também, é possível notar que, à primeira vista, o índice CRB parece antecipar as recessões reportadas no gráfico, embora sejam necessários testes adicionais para confirmar esse diagnóstico. 
Gráfico 6

Primeiras diferenças dos logaritmos naturais do Índice de preços CRB e dos Índices de produção industrial nacional e estadual, 1998:01/2009:04 (dados trimestrais)

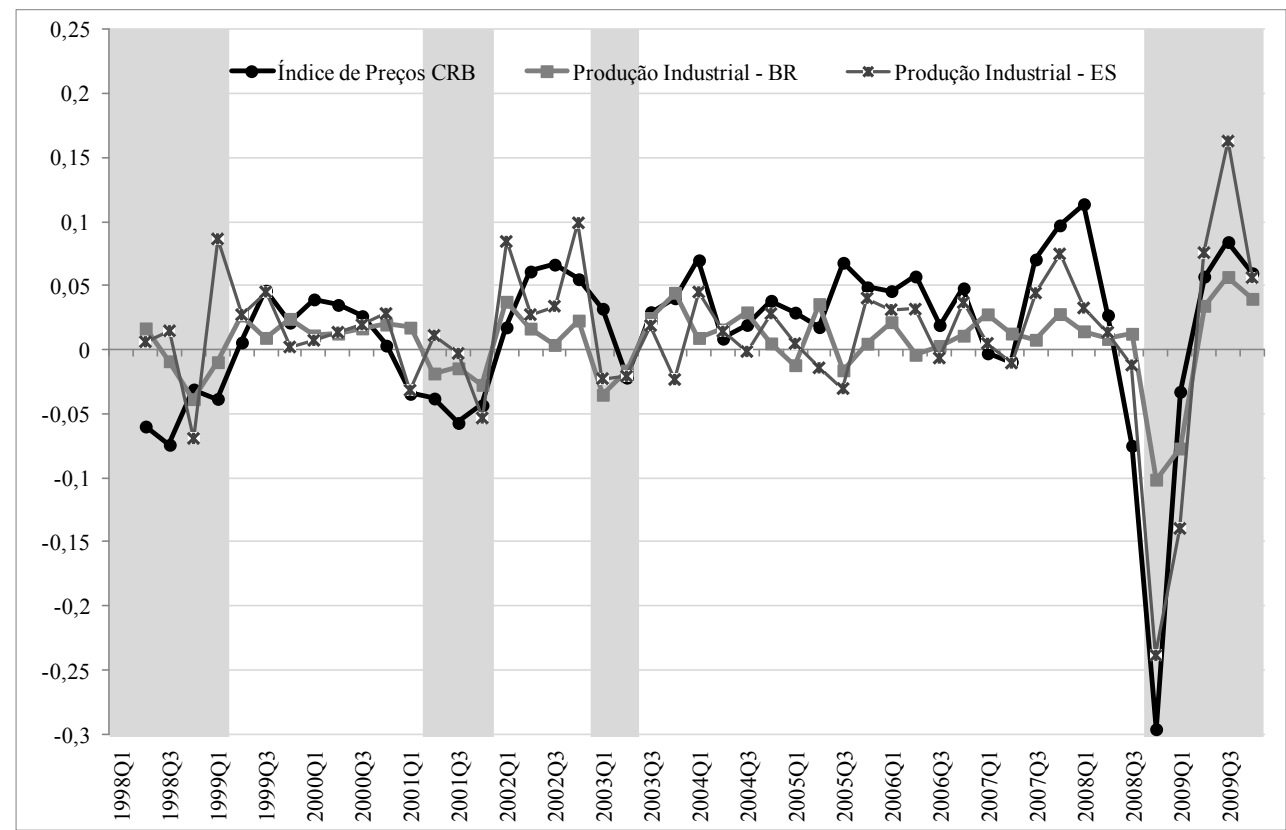

Fonte: Cálculos do autor, com base em dados do CRB e do IBGE.

Gráfico 7

Componentes cíclicos do Índice de preços CRB e dos Índices de produção industrial nacional e estadual, 1998:01/2009:04 (dados trimestrais)

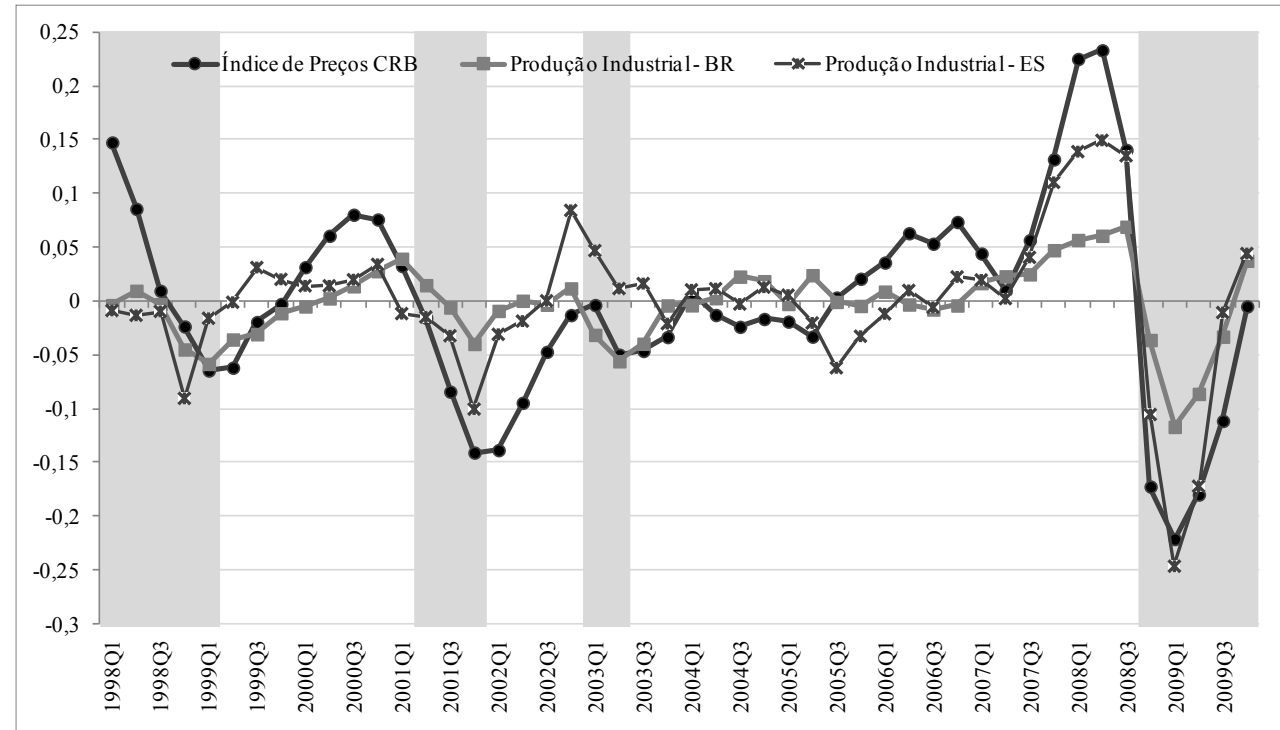

Fonte: Cálculos do autor, com base em dados do CRB e do IBGE. 
O Gráfico 8 apresenta diagramas de dispersão, relacionando os índices de produção industrial nacional (diagramas à esquerda) e estadual (diagramas à direita) e o índice CRB. Os gráficos da parte superior expõem as primeiras diferenças dos logaritmos naturais enquanto os da parte inferior, os componentes cíclicos das séries. Esses gráficos também contêm retas de regressão obtidas a partir do método de mínimos quadrados ordinários (MMQO).

\section{Gráfico 8}

Diagramas de dispersão entre Índice de preços CRB e Índices de produção industrial nacional e estadual, 1998:01/2009:04 (dados trimestrais)

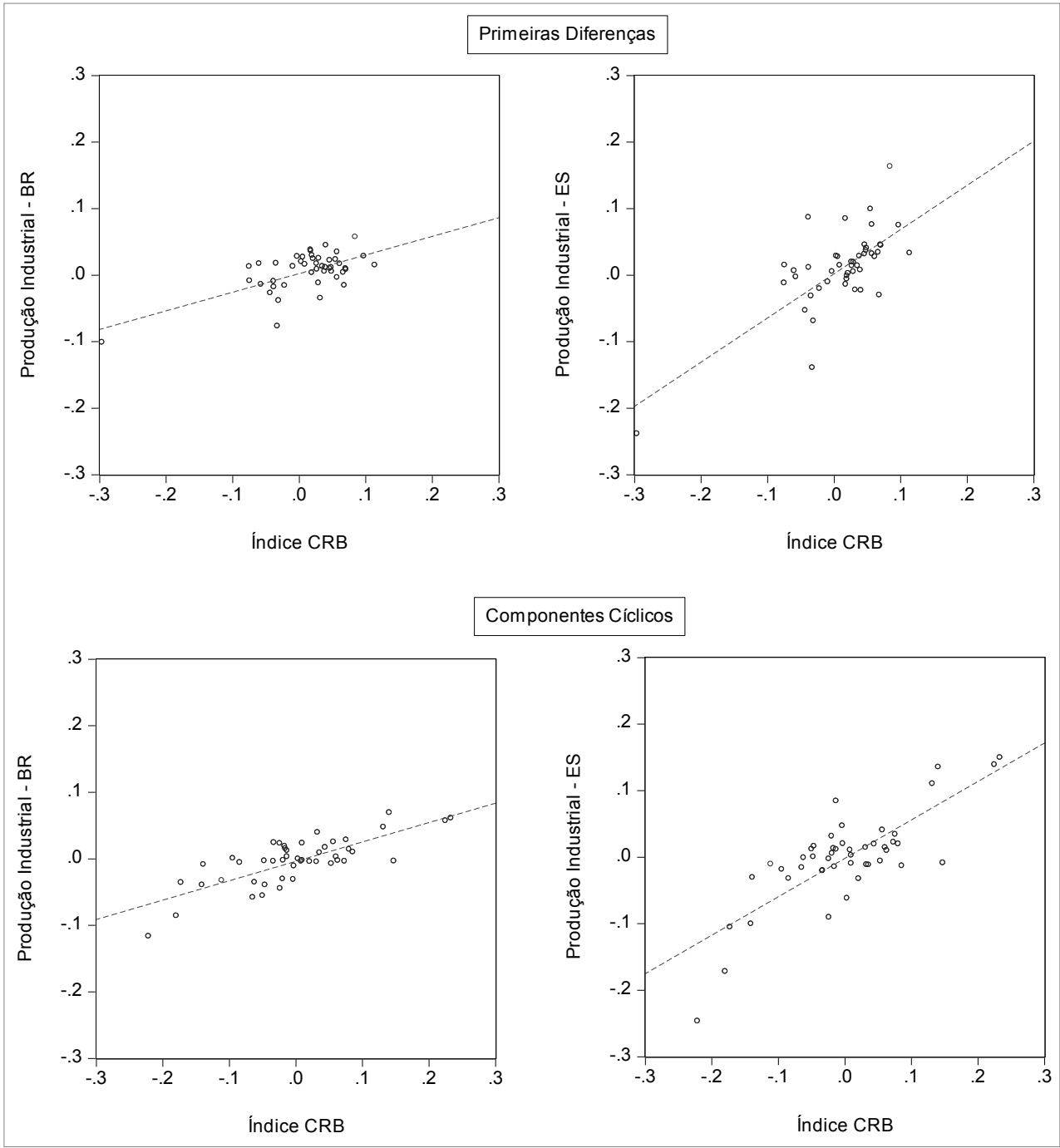

Fonte: Cálculos do autor, com base em dados do CRB e do IBGE. 
Pode-se notar que, tanto no caso de dados em primeiras diferenças quanto dados filtrados, as retas de regressão estimadas para o estado do Espírito Santo são mais inclinadas do que as estimadas para o Brasil, resultado que denota maior grau de associação linear entre as variáveis citadas no caso estadual. Esse fato é corroborado pelos valores relativamente mais altos dos coeficientes de determinação no caso estadual vis-à-vis o caso nacional ${ }^{15}$.

A Tabela 3 expõe os coeficientes de correlação estimados entre pares de variáveis, no caso de ambas as transformações supracitadas.

Tabela 3

Coeficientes de correlação entre Índices de produção industrial e Índice de preços de commodities, 1998:01/2009:04 (dados trimestrais)

\begin{tabular}{l|c|c|c}
\hline Primeiras diferenças & $\begin{array}{c}\text { Produção Industrial - } \\
\text { BR }\end{array}$ & $\begin{array}{c}\text { Produção Industrial - } \\
\text { ES }\end{array}$ & Índice CRB \\
\hline Produção Industrial - BR & 1 & & \\
\hline Produção Industrial - ES & 0,774 & 1 & \\
\hline Índice CRB & 0,633 & 0,716 & 1 \\
\hline Componentes Cíclicos & $\begin{array}{c}\text { Produção Industrial - } \\
\text { BR }\end{array}$ & Produção Industrial - ES & Índice CRB \\
\hline Produção Industrial - BR & 1 & & \\
\hline Produção Industrial - ES & 0,777 & 1 & 1 \\
\hline Índice CRB & 0,772 & 0,791 & \\
\hline Fon Cála
\end{tabular}

Fonte: Cálculos do autor, com base em dados do CRB e do IBGE.

Também, no caso dessas tabelas, pode-se notar a ocorrência de um maior grau de associação linear entre o índice CRB e o de produção industrial do Espírito Santo, em comparação ao de produção industrial brasileiro. Esse resultado confirma aqueles reportados acima, embora nada diga a respeito de relações de precedência temporal e/ou causalidade entre as variáveis consideradas. Nas próximas subseções do trabalho, será desenvolvida uma análise empírica, a fim de explorar a possível existência de tais padrões.

\subsection{Testes de Raiz Unitária}

Um importante passo da análise empírica a ser conduzida no presente contexto equivale a checar a estacionariedade das séries temporais analisadas. Por conta disso, optou-se pela realização de testes de raiz unitária.

A Tabela 4 contém resultados dos testes Augmented Dickey-Fuller (ADF) (Dickey; Fuller 1981) e Phillips-Perron (PP) (Phillips; Perron 1988), cuja hipótese

(15) Os coeficientes de determinação $(R 2)$ relacionados a regressões, envolvendo os índices supracitados e uma constante foram os seguintes, nos casos nacional e estadual, respectivamente: 0,39 e 0,5 para dados em primeiras diferenças e 0,59 e 0,62 , para componentes cíclicos das séries. 
nula equivale à ocorrência de uma raiz unitária em cada série. No caso desses testes, todos os resultados foram obtidos a partir de especificações com uma constante e tendência temporal. O número de defasagens empregado em cada teste foi escolhido a partir do Critério de Informação de Schwarz, sendo reportado entre parênteses, na tabela.

A título de fornecer maior robustez aos resultados oriundos de tais testes, a tabela ainda inclui resultados referentes ao teste KPSS, cuja hipótese nula, contrariamente aos testes anteriores, equivale à hipótese de estacionariedade da série. Adicionalmente, também são reportados resultados referentes a esse teste no caso de quatro defasagens, de acordo com sugestões contidas na última referência (Kwiatkowski et al., 1992).

Tabela 4

Testes de raiz unitária

Período amostral: 1998:01/2009:03 (dados trimestrais)

\begin{tabular}{|c|c|c|c|c|}
\hline Variável & $\begin{array}{l}\text { Teste } \\
\text { ADF }\end{array}$ & $\begin{array}{c}\text { Teste } \\
\text { PP }\end{array}$ & $\begin{array}{l}\text { Teste } \\
\text { KPSS }\end{array}$ & $\begin{array}{c}\text { Teste } \\
\text { KPSS } \\
\text { (4 defasagens) }\end{array}$ \\
\hline \multirow{2}{*}{ Índice CRB } & $-3,503^{*}$ & $-2,78$ & $0,163 * *$ & \multirow{2}{*}{$0,163 * *$} \\
\hline & (1) & (2) & (4) & \\
\hline \multirow{2}{*}{$\Delta$ (Índice CRB ) } & $-4,59 * * *$ & $-3,20 *$ & 0,093 & \multirow{2}{*}{0,105} \\
\hline & (1) & (14) & (3) & \\
\hline \multirow{2}{*}{ Produção Industrial - BR } & $-5,24 * * *$ & $-3,70 * *$ & 0,089 & \multirow{2}{*}{0,089} \\
\hline & (1) & (5) & (4) & \\
\hline \multirow{2}{*}{$\Delta$ (Produção Industrial - BR ) } & $-7,41 * * *$ & $-6,64 * * *$ & $0,129 *$ & \multirow{2}{*}{0,042} \\
\hline & $(1)$ & (8) & $(12)$ & \\
\hline \multirow{2}{*}{ Produção Industrial - ES } & $-5,06 * * *$ & $-3,35^{*}$ & 0,118 & \multirow{2}{*}{0,118} \\
\hline & (1) & (5) & (4) & \\
\hline \multirow{2}{*}{$\Delta$ (Produção Industrial - ES) } & $-6,70 * * *$ & $-7,85 * * *$ & 0,106 & \multirow{2}{*}{0,031} \\
\hline & (3) & (16) & (13) & \\
\hline
\end{tabular}

Notas: (a) Todas as séries estão expressas em escala logarítmica natural.

(b) Valores críticos para esses testes estão contidos em Dickey; Fuller (1981), Mackinnon (1991) e Kwiatkowski et al. (1992).

(c) O número de defasagens empregado em cada teste (reportado em parênteses) foi escolhido de acordo com o Critério de Informação de Schwarz.

(d) Os termos $(*),(* *)$ e $(* * *)$ denotam rejeição da hipótese nula de cada teste em níveis de $10 \%$, $5 \%$ e $1 \%$ de significância, respectivamente.

Fonte: Cálculos do autor, com base em dados do CRB e do IBGE.

De acordo com os resultados contidos na tabela, é possível notar que a maioria das séries analisadas pode ser caracterizada como pertencentes à classe I(1), ou seja, essas séries são integradas de primeira ordem. Por outro lado, também, é possível notar que os resultados dos testes considerados demonstram que as séries de produção industrial podem ser caracterizadas como estacionárias 
em níveis $(\mathrm{I}(0))$, fato que impossibilita, em princípio, a condução de testes de cointegração entre essas séries e o índice $\mathrm{CRB}^{16}$. Em decorrência disso, optou-se por trabalhar com transformações estacionárias das séries. Especificamente, no caso da presente análise, as transformações utilizadas equivalem ao uso de primeiras diferenças dos logaritmos naturais e de componentes cíclicos das séries, em consonância com alguns dos resultados apresentados acima.

\subsection{Testes de Granger-Causalidade}

Os resultados dos Gráficos 6 e 7, referentes à evolução temporal de transformações estacionárias das séries sugerem a ocorrência de um padrão de precedência temporal entre o índice $\mathrm{CRB}$ e os de produção industrial considerados. Por conta disso, a Tabela 5 busca responder à seguinte questão: ocorre algum padrão de precedência temporal entre preços de commodities e nível de atividade? Para tanto, são expostos resultados de testes de Granger-causalidade (Granger, 1969) ${ }^{17}$.

A Tabela 5 apresenta resultados dos testes citados para os contextos nacional e estadual, tanto no caso de dados em primeiras diferenças quanto no de componentes cíclicos. Basicamente, essa tabela reporta os p-valores associados à hipótese nula do teste.

Tabela 5

Testes de Granger-causalidade envolvendo medidas de preços de commodities e nível de atividade: Brasil e Espírito Santo

\begin{tabular}{l|c|c|c|c}
\hline & \multicolumn{2}{|c|}{ Primeiras Diferenças } & \multicolumn{2}{c}{ Componentes Cíclicos } \\
\hline & $\begin{array}{c}\text { Produção } \\
\text { Industrial } \\
\text { Brasil }\end{array}$ & $\begin{array}{c}\text { Produção } \\
\text { Industrial } \\
\text { Espírito Santo }\end{array}$ & $\begin{array}{c}\text { Produção } \\
\text { Industrial } \\
\text { Brasil }\end{array}$ & $\begin{array}{c}\text { Produção } \\
\text { Industrial } \\
\text { Espírito Santo }\end{array}$ \\
\hline $\begin{array}{l}\text { H0: Índice CRB não } \\
\begin{array}{l}\text { Granger-causa } \\
\text { Nivel de Atividade }\end{array}\end{array}$ & $0,003 * * *$ & $0,000^{* * *}$ & $0,004 * * *$ & $0,000 * * *$ \\
\hline
\end{tabular}

Notas: (a) Foram empregadas quatro defasagens nos testes de Granger-causalidade.

(b) $\mathrm{Na}$ tabela, são reportados os p-valores associados à hipótese nula do teste $\left(\mathrm{H}_{0}\right.$ : "Índice $\mathrm{CRB}$ não Granger-causa Nível de Atividade").

(c) Os termos $(*),(* *)$ e $(* * *)$ denotam rejeição da hipótese nula do teste em níveis de significância de $10 \%, 5 \%$ e $1 \%$, respectivamente.

Fonte: Cálculos do autor, com base em dados do CRB e do IBGE.

Os resultados reportados na Tabela 5 demonstram que o índice CRB exerce um padrão de precedência temporal sobre o nível de atividade, tanto no

(16) Ver, a esse respeito, Engle e Granger (1987).

(17) Para exemplos de aplicações desse teste a distintos contextos, ver, além da referência original, Sims (1972) e Thurman; Fischer (1988). 
caso do índice de produção industrial nacional quanto no que se refere ao índice estadual, independentemente da transformação estacionária considerada, uma vez que a hipótese nula do teste é rejeitada em todos os casos acima, em nível de significância de 1\%. Em termos gerais, os resultados obtidos demonstram que o comportamento desse índice de preços de commodities pode vir a prever, com certa antecedência, os níveis de atividade do estado e do país (maiores detalhes adiante).

Uma questão relacionada aos resultados citados diz respeito ao fato de os preços de commodities afetarem ou não outras variáveis econômicas do estado do Espírito Santo. A Tabela 6 busca verificar essa alternativa ao expor resultados de testes de Granger-causalidade, relacionando o índice de preços CRB e diversas variáveis econômicas selecionadas para o estado: importações, exportações, horas pagas na indústria, pessoal ocupado na indústria, índices de produção industrial referentes a setores específicos (alimentação, celulose, extrativa, metalurgia, minerais não metálicos, transformação) e vendas no varejo.

Tabela 6

Testes de Granger-causalidade, envolvendo preços de commodities e variáveis econômicas selecionadas: Espírito Santo

\begin{tabular}{l|c|c}
\hline H0: Índice CRB não Granger-causa & $\begin{array}{c}\text { Primeiras } \\
\text { Diferenças }\end{array}$ & $\begin{array}{c}\text { Componentes } \\
\text { Cíclicos }\end{array}$ \\
\hline Impóvel Econômica & $0,004^{* * *}$ & $0,003^{* *}$ \\
\hline Exportações & $0,000^{* * *}$ & $0,000^{* * *}$ \\
\hline Horas Pagas na Indústria & 0,359 & 0,476 \\
\hline Pessoal Ocupado na Indústria & 0,271 & 0,517 \\
\hline Produção Industrial - Alimentação & 0,682 & 0,598 \\
\hline Produção Industrial - Celulose & $0,005^{* * *}$ & $0,009^{* * *}$ \\
\hline Produção Industrial - Extrativa & $0,000^{* * *}$ & $0,000^{* * *}$ \\
\hline Produção Industrial - Metalurgia & $0,010^{* *}$ & $0,008^{* * *}$ \\
\hline Produção Industrial - Minerais & 0,24 & 0,176 \\
\hline Produção Industrial - Transformação & $0,000^{* * *}$ & $0,000^{* * *}$ \\
\hline Vendas Varejo & 0,584 & 0,49 \\
\hline Notas: (a) Iora
\end{tabular}

Notas: (a) Foram empregadas quatro defasagens nos testes de Granger-causalidade.

(b) $\mathrm{Na}$ tabela são reportados os p-valores associados à hipótese nula do teste $\left(\mathrm{H}_{0}\right.$ : "Índice CRB não Granger-causa Variável Econômica").

(c) Os termos $(*),(* *)$ e $(* * *)$ denotam rejeição da hipótese nula do teste em níveis de significância de $10 \%, 5 \%$ e $1 \%$, respectivamente.

Fonte: Cálculos do autor, com base em dados do CRB e do IBGE.

No caso desses testes específicos, os resultados obtidos demonstram que pouco mais de metade das séries consideradas (seis em onze) sofrem precedência temporal do índice CRB. Significa que preços de commodities Granger-causam importações, exportações e índices de produção industrial das indústrias de 
celulose, extrativa, metalúrgica e de transformação do estado. São resultados importantes no sentido de chamar atenção para o fato de que a evolução temporal dos preços de commodities, captada a partir do índice CRB, pode vir a fornecer indicações aproximadas do comportamento futuro da economia estadual ${ }^{18}$.

\subsection{Impactos dinâmicos de preços de commodities sobre o nível de atividade}

Uma forma de se investigar os efeitos dinâmicos de preços de commodities sobre o nível de atividade é por meio da estimação de um modelo de Vetores Autorregressivos (VAR). Especificamente, a partir dessa metodologia, é possível estimar a resposta de medidas, representando o nível de atividade econômica a variações nos preços de commodities ao longo do tempo. No caso, quer-se estimar um modelo no seguinte formato ${ }^{19}$ :

$$
A X_{t}=B_{0}+\sum_{i=1}^{p} B_{i} X_{t-i}+B \epsilon_{t}
$$

em que:

$A$ é uma matriz $\mathrm{n} \times \mathrm{n}$ que define restrições contemporâneas entre as variáveis as quais constituem o vetor $\mathrm{n} \times 1, X_{t}$, com

$$
X_{t}=[\text { Índice } C R B ; \text { Índice de Produção Industrial }]^{r}
$$

equivalendo a um vetor que contém todas as $n$ variáveis empregadas na estimação $\operatorname{VAR}(\mathrm{n}=2 \text {, no caso })^{20}$.

$B_{0}$ equivale a um vetor de constantes $\mathrm{n} \times 1$, ao passo que $B_{i}$ equivale a matrizes $\mathrm{n} \times \mathrm{n} . B$ equivale a uma matriz diagonal $\mathrm{n} \times \mathrm{n}$ de desvios-padrão.

O termo $i$ equivale ao número de defasagens empregado no VAR, com o termo $p$ equivalendo ao número máximo de defasagens.

Por sua vez, o termo $\epsilon_{t}$ equivale a um vetor $\mathrm{n} \times 1$ de perturbações aleatórias não correlacionadas entre si contemporânea ou temporalmente. Esse vetor tem média zero e variância constante e normalizada para igualar a unidade, equivalendo a uma matriz identidade de ordem $n$, no presente contexto:

$$
\epsilon_{t} \sim i . i . d .\left(0 ; I_{n}\right)
$$

(18) Uma sugestão nesse sentido seria a construção de indicadores antecedentes relacionados à economia do estado do Espírito Santo, em moldes semelhantes àqueles propostos por Bonelli, Bastos e Abreu (2009). No caso, seria desejável que tais indicadores fossem baseados no comportamento de índices de preços de commodities, dada a estrutura produtiva local.

(19) A exposição da metodologia VAR aqui descrita é baseada em Bueno (2008, cap.6).

(20) Os choques no VAR foram identificados com base nesse ordenamento das variáveis (com o índice CRB vindo antes do índice de produção industrial) e na decomposição de Cholesky (ver Enders 1995, cap.5). 
Por outro lado, por conta da possível endogeneidade existente entre as variáveis do VAR, costuma-se estimar modelos desse tipo a partir de sua forma reduzida, que pode ser representada pela seguinte equação:

$$
\begin{aligned}
& X_{t}=A^{-1} B_{0}+\sum_{i=1}^{p} A^{-1} B_{i} X_{t-i}+A^{-1} B \epsilon_{t} \\
& =\Phi_{0}+\sum_{i=1}^{p} \Phi_{i} X_{t-i}+e_{t},
\end{aligned}
$$

em que:

$$
\Phi_{i} \equiv A^{-1} B_{i}, i=0,1, \ldots, p \quad B \epsilon_{t} \equiv A e_{t} .
$$

O modelo VAR descrito acima pode ser estimado via MMQO, atentandose, principalmente, para a interação entre as variáveis do sistema considerado.

Todos os dados contidos nos VARs estimados equivalem a primeiras diferenças dos logaritmos naturais das séries ${ }^{21}$. Esse procedimento é justificado a partir do fato de que, por terem sido os modelos VAR em questão estimados via MMQO, optou-se pelo uso de variáveis estacionárias de forma a evitar-se problemas de regressão espúria. Cada VAR foi estimado com uma constante e três defasagens das variáveis citadas acima, assim como dummies para períodos específicos, escolhidas de modo a refletir choques macroeconômicos ocorridos nessas ocasiões ${ }^{22}$.

O Gráfico 9 apresenta as funções Impulso Resposta (FIR) acumuladas estimadas para um período equivalente a 40 trimestres (10 anos). Especificamente, o gráfico à esquerda corresponde à situação em que o nível de atividade é representado pelo índice de produção industrial nacional e o gráfico à direita, ao caso estadual. Em ambos os gráficos, linhas contínuas equivalem às FIR propriamente ditas, enquanto linhas tracejadas, a intervalos de confiança correspondentes a dois erros-padrão. As escalas dos gráficos foram uniformizadas de modo a facilitar a comparação de resultados.

À primeira vista, os gráficos demonstram um padrão semelhante entre os casos nacional e estadual. Um aumento de um desvio-padrão nos preços de commodities exerce, em um primeiro momento, um impacto positivo sobre o nível de atividade, que atinge um pico em torno de quatro trimestres (um ano) após o choque inicial para, em seguida, alcançar um nível permanentemente mais alto.

(21) Resultados não mudam no caso de estimações VAR envolvendo componentes cíclicos das séries. Esses resultados não foram reportados apenas com o intuito de poupar espaço.

(22) Foram criadas dummies temporais para os seguintes trimestres da amostra: 1999:01, 2002:01, 2003:01 e 2008:03. Esses períodos foram escolhidos de modo a refletir o padrão temporal do índice CRB, assim como os efeitos de eventos econômicos específicos sobre esse índice. Resultados obtidos são basicamente os mesmos no caso de especificações VAR em que essas dummies não são inclusas. 
Por outro lado, vale notar a ocorrência de algumas diferenças entre os casos nacional e estadual. Pode-se notar que o nível de atividade estadual alcança, após 40 trimestres, um nível permanente mais alto do que o de atividade nacional. Em particular, no caso estadual, o nível de atividade sofre um aumento permanente, ficando em um patamar cerca de $2,5 \%$ mais alto do que na situação inicial de equilíbrio.

Gráfico 9

Impactos dinâmicos de preços de commodities sobre o nível de atividade:

Brasil e Espírito Santo

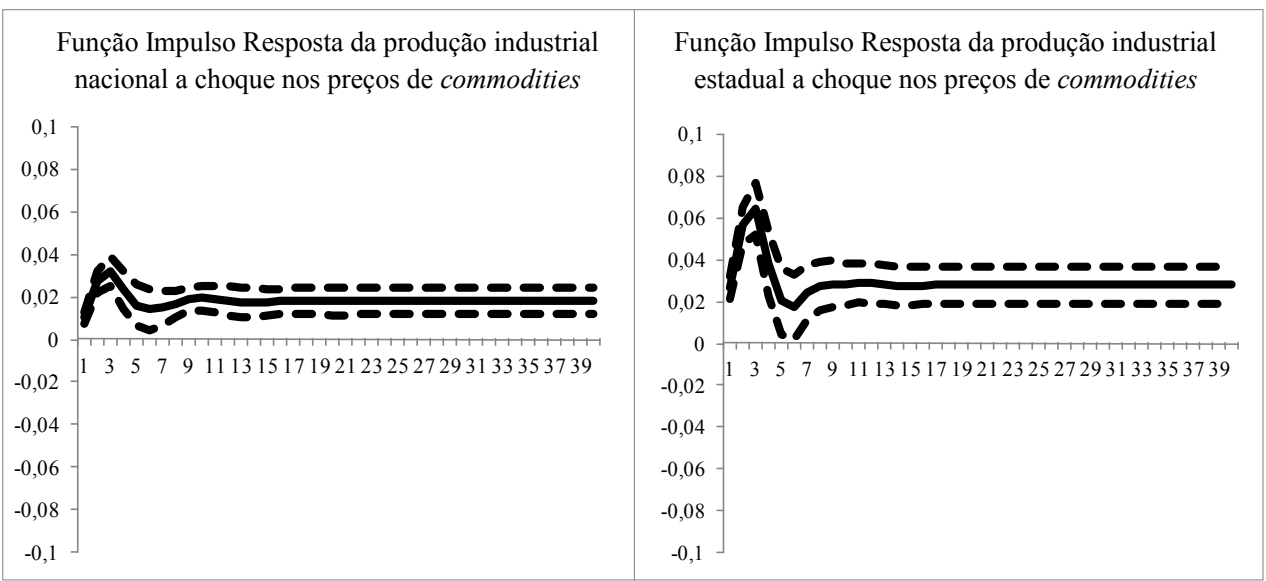

Notas: (a) Funções Impulso Resposta (FIR) obtidas a partir de especificações VAR, contendo o índice CRB (representando preços de commodities) e índices de produção industrial (nível de atividade) nacional e estadual. Em cada especificação, foram empregadas três defasagens e quatro dummies temporais.

(b) Linhas contínuas equivalem a FIR estimadas, enquanto linhas tracejadas equivalem a intervalos de confiança correspondentes a dois erros-padrão.

Fonte: Cálculos do autor, com base em dados do CRB e do IBGE.

Esses resultados são importantes no sentido de demonstrarem que preços de commodities exercem um impacto positivo permanente sobre o nível de atividade, tanto no contexto nacional quanto no estadual, embora seja nitidamente maior no segundo caso. Por sua vez, um resultado nesses moldes confirma que o estado sofre mais com as oscilações advindas dos preços desses bens vis-à-vis o país.

Adicionalmente, o Gráfico 10 contém as Funções Impulso Resposta estimadas a partir da mesma especificação VAR para distintos estados brasileiros, além do Espírito Santo. Nesse caso, é possível notar que o nível de atividade estadual (linha tracejada) alcança um nível de equilíbrio de longo prazo permanentemente mais alto do que os demais estados analisados. 
O gráfico demonstra que o estado do Espírito Santo sofre, em geral, um impacto nitidamente maior de variações nos preços de commodities do que os demais estados analisados.

Gráfico 10

Funções Impulso Resposta estimadas para distintos estados brasileiros Resposta dinâmica a um desvio-padrão de + ou -2 erros-padrão (Decomposição de Cholesky)

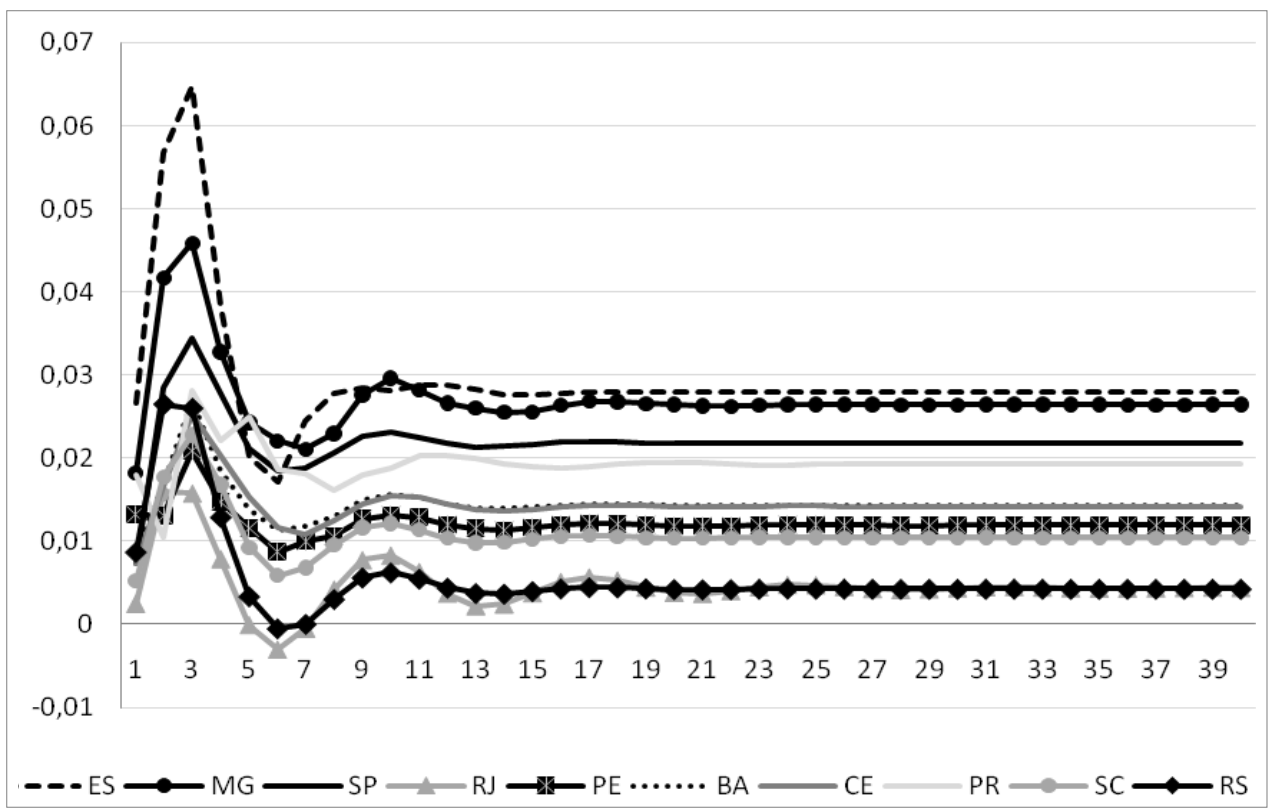

Notas: (a) Funções Impulso Resposta (FIR) obtidas a partir de especificações VAR, contendo o índice CRB (representando preços de commodities) e índices de produção industrial (nível de atividade) nacional e estadual.

(b) Em cada especificação VAR, foram empregadas três defasagens e quatro dummies temporais. Fonte: Cálculos do autor, com base em dados do CRB e do IBGE.

Uma questão que poderia surgir no presente contexto é a seguinte: há alguma diferença em termos de impactos de variações de preços de commodities em uma economia de acordo com seu grau de abertura ao exterior? O Gráfico 11 busca responder a essa questão. Especificamente, esse gráfico equivale a um diagrama de dispersão, relacionando os impactos de choques em preços de commodities e coeficientes de grau de abertura para distintos estados brasileiros, sendo exposta também uma reta de regressão obtida via $\mathrm{MMQO}^{23}$.

(23) No caso, os impactos de choques em preços de commodities são mensurados como o primeiro valor reportado para Funções Impulso Reposta obtidas a partir de uma especificação VAR, envolvendo os índices CRB e de produção industrial nos moldes descritos acima. Os coeficientes de grau de abertura para os estados equivalem às estimativas contidas em Pereira e Maciel (2010). Os resultados obtidos são virtualmente os mesmos no caso dos componentes cíclicos das séries. Esses resultados não foram reportados no texto apenas com o intuito de poupar espaço. 
Gráfico 11

Grau de abertura x impacto inicial de choques de preços de commodities sobre nível de atividade, estados brasileiros (primeiras diferenças dos logaritmos naturais)

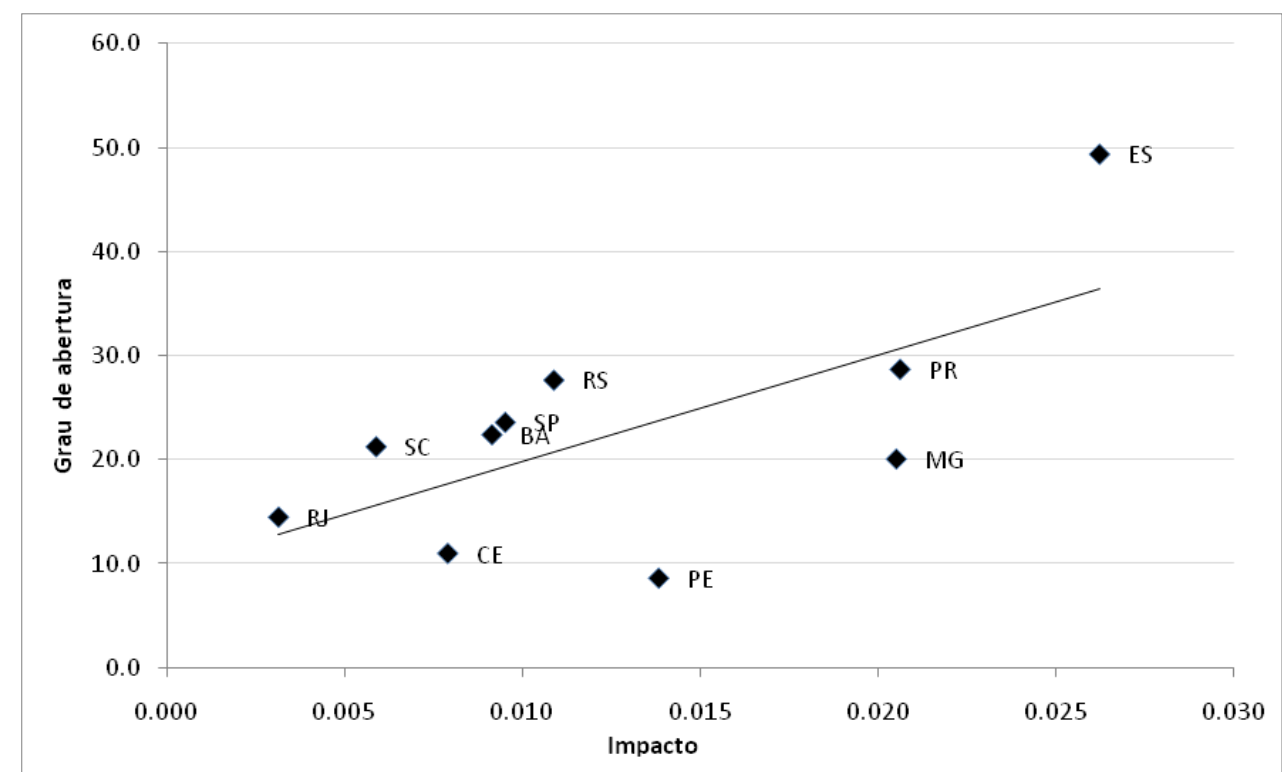

Notas: (a) Coeficientes de grau de abertura para os estados equivalem às estimativas contidas em Pereira e Maciel (2010).

(b) O impacto inicial de choques de preços de commodities sobre o nível de atividade são mensurados como o primeiro valor reportado para Funções Impulso Resposta (FIR) obtidas a partir de uma especificação VAR envolvendo os índices CRB e de produção industrial de cada estado. Fonte: Cálculos do autor, com base em dados do CRB e Pereira e Maciel (2010).

Os resultados descritos no diagrama de dispersão apresentado demonstram a ocorrência de uma relação empírica positiva entre os impactos de choques nos preços de commodities e grau de abertura, ou seja, no caso dos estados brasileiros analisados, tem-se uma situação em que economias mais abertas ao comércio exterior são, em média, economias mais impactadas por variações nos preços de commodities.

Em especial, chama atenção o comportamento do estado do Espírito Santo, localizado a uma distância considerável da reta de regressão estimada e com valores relativamente altos para ambas as variáveis (impacto dos choques e grau de abertura), o que reforça a constatação de que o estado provavelmente sofre de maneira mais intensa os impactos de variações nos preços de commodities. Uma maneira formal de checar essa hipótese equivale a um exercício de decomposição da variância. Basicamente, esse exercício pode ser feito a partir do cálculo da porcentagem da variância do erro de previsão de uma das variáveis do 
VAR em relação a outras variáveis do sistema, bem como sua evolução ao longo do tempo ${ }^{24}$.

A Tabela 7 contém resultados relacionados a um exercício de decomposição da variância, tanto no caso nacional (segunda coluna) quanto no caso estadual (terceira coluna). Por sua vez, a quarta coluna dessa tabela equivale à divisão da terceira pela segunda coluna, com o intuito de verificar a ocorrência de eventuais diferenças de magnitude entre Brasil e Espírito Santo no que diz respeito aos impactos quantitativos de choques nos preços de commodities. Consideram-se distintos períodos (1 a 60 trimestres, expressos em múltipos de quatro, de modo a refletir a frequência trimestral adotada), como forma de se checar a importância dos choques supracitados ao longo de distintos horizontes de tempo.

Tabela 7

Decomposição da variância - Impactos quantitativos de choques nos preços de commodities sobre o nível de atividade, Brasil e Espírito Santo

\begin{tabular}{|c|c|c|c|}
\hline \multirow[b]{2}{*}{ Período } & \multicolumn{2}{|c|}{$\begin{array}{l}\text { Choque preços commodities } \\
\text { Primeiras diferenças }\end{array}$} & \multirow[b]{2}{*}{$(2) /(1)$} \\
\hline & Brasil (1) & Espírito Santo (2) & \\
\hline 1 & 26,993 & 47,379 & 1,755 \\
\hline 4 & 59,711 & 69,467 & 1,163 \\
\hline 8 & 61,542 & 68,779 & 1,118 \\
\hline 12 & 61,799 & 68,769 & 1,113 \\
\hline 24 & 61,816 & 68,772 & 1,116 \\
\hline 36 & 61,815 & 68,772 & 1,113 \\
\hline 48 & 61,815 & 68,772 & 1,113 \\
\hline 60 & 61,815 & 68,772 & 1,113 \\
\hline \multirow[t]{2}{*}{ Média } & 57,163 & 66,185 & 1,199 \\
\hline & \multicolumn{2}{|c|}{$\begin{array}{l}\text { Choque preços commodities } \\
\text { Componentes cíclicos }\end{array}$} & \\
\hline Período & Brasil (1) & Espírito Santo (2) & $(2) /(1)$ \\
\hline 1 & 27,080 & 46,240 & 1,707 \\
\hline 4 & 72,803 & 78,512 & 1,078 \\
\hline 8 & 79,206 & 84,834 & 1,071 \\
\hline 12 & 79,931 & 85,562 & 1,070 \\
\hline 24 & 80,213 & 86,066 & 1,072 \\
\hline 36 & 80,222 & 86,082 & 1,073 \\
\hline 48 & 80,222 & 86,083 & 1,073 \\
\hline 60 & 80,222 & 86,083 & 1,073 \\
\hline Média & 72,488 & 79,933 & 1,152 \\
\hline
\end{tabular}

Nota: (a) Resultados de exercícios de decomposição da variância obtidos a partir de especificações VAR, incluindo uma constante e três defasagens de cada variável, assim como dummies para períodos específicos.

Fonte: Cálculos do autor, com base em dados do CRB e do IBGE.

(24) Para maiores detalhes a esse respeito, ver Bueno (2008, cap. 6). 
Os resultados contidos na tabela demonstram que ocorrem diferenças entre o estado e o país no que diz respeito à contribuição relativa de choques nos preços de commodities. Em particular, no caso da quarta coluna da tabela, pode-se notar que a contribuição de choques desse tipo é, em média, cerca de 1,2 vezes superior no caso do Espírito Santo quando da comparação com o Brasil. Esse resultado reforça os anteriores que demonstravam um maior impacto relativo de choques em preços de commodities no estado, um resultado decorrente da própria estrutura produtiva local.

Por outro lado, quando da comparação dos valores contidos na segunda e terceira colunas da tabela, é possível notar que os impactos de variações nos preços de commodities tendem a ser mais pronunciados no estado, também. Assim, no caso de um trimestre após o choque, tem-se que preços de commodities explicam cerca de $47 \%$ da variância na produção industrial do Espírito Santo, sendo essa proporção equivalente a apenas $27 \%$, no caso brasileiro (impacto quase duas vezes maior no caso estadual do que no caso nacional). No caso de quatro trimestres (um ano) após o choque, a contribuição desses choques para a variância dos índices de produção industrial estadual e nacional corresponde a 69\% e 60\%, aproximadamente (79\% e $73 \%$, no caso de componentes cíclicos), com essa proporção sendo mantida até mesmo no caso de 60 trimestres (15 anos) depois. Em média, o impacto de choques em preços de commodities fica em torno de torno de $57 \%$ sobre o nível de atividade nacional, equivalendo o mesmo a $66 \%$, no caso do nível de atividade estadual (no caso de componentes cíclicos das séries, esses impactos equivalem a $72 \%$ e $80 \%$ dos níveis de atividade nacional e estadual, respectivamente).

Em suma, a partir do exercício de decomposição da variância descrito, pode-se notar a ocorrência de dois resultados básicos: (i) existem nítidas diferenças quantitativas relacionadas aos impactos de choques nos preços de commodities entre o país e o estado, com essas diferenças sendo mais pronunciadas no caso de curtos horizontes de tempo; (ii) choques nos preços de commodities possuem, em média, um impacto cerca de 1,2 vezes superior no caso estadual em comparação ao caso nacional, independentemente da transformação estacionária considerada.

\section{Testes de robustez}

Nesta seção, são expostos resultados de testes de robustez. Aqui, a intenção básica equivale a verificar se os principais resultados empíricos descritos anteriormente são robustos a variações nos métodos de análise e/ou dados. A título de simplificação, os testes de robustez expostos abaixo foram divididos em duas categorias básicas: (i) uso de distintos números de defasagens empregados em testes de Granger-causalidade; (ii) uso de índices alternativos de preços de commodities. As subseções abaixo discutem esses testes em maior detalhe. 


\subsection{Variações no número de defasagens utilizadas em testes de Granger- causalidade}

Uma vez que resultados de testes de Granger-causalidade podem ser sensíveis ao número de defasagens empregado nos testes, optou-se por verificar a robustez dos principais resultados obtidos acima a partir da execução de testes dessa natureza com distintos números de defasagens (1, 4 e 8 defasagens). Os resultados estão expostos na Tabela 8 .

Tabela 8

Robustez: testes de Granger-causalidade com números de defasagens alternativos (1, 4, 8 defasagens), Brasil e Espírito Santo

\begin{tabular}{|c|c|c|c|c|c|}
\hline & & \multicolumn{2}{|c|}{ Primeiras Diferenças } & \multicolumn{2}{|c|}{ Componentes Cíclicos } \\
\hline $\begin{array}{l}\text { HO: Índice CRB não } \\
\text { Granger-causa } \\
\text { Nivel de Atividade }\end{array}$ & Defasagem & $\begin{array}{c}\text { Produção } \\
\text { Industrial } \\
\text { Brasil }\end{array}$ & $\begin{array}{c}\text { Produção } \\
\text { Industrial } \\
\text { Espírito Santo }\end{array}$ & $\begin{array}{c}\text { Produção } \\
\text { Industrial } \\
\text { Brasil }\end{array}$ & $\begin{array}{c}\text { Produção } \\
\text { Industrial } \\
\text { Espírito Santo }\end{array}$ \\
\hline \multirow{3}{*}{ Índice CRB } & 1 & $0,000 * * *$ & $0,000 * * *$ & $0,035 * *$ & 0,252 \\
\hline & 4 & $0,003 * * *$ & $0,000 * * *$ & $0,004 * * *$ & $0,000 * * *$ \\
\hline & 8 & $0,004 * * *$ & $0,029 * *$ & $0,001 * * *$ & $0,007 * * *$ \\
\hline
\end{tabular}

Notas: (a) Foram empregados números alternativos de defasagens (1, 4 e 8 ) nos testes de Grangercausalidade.

(b) $\mathrm{Na}$ tabela, são reportados os p-valores associados à hipótese nula do teste $\left(\mathrm{H}_{0}\right.$ : “Índice $\mathrm{CRB}$ não Granger-causa Nível de Atividade").

(c) Os termos $(*),(* *)$ e $(* * *)$ denotam rejeição da hipótese nula do teste aos níveis de significância de $10 \%, 5 \%$ e $1 \%$, respectivamente.

Fonte: Cálculos do autor, com base em dados do CRB e do IBGE.

De acordo com a informação contida na tabela, pode-se notar que os resultados obtidos anteriormente são robustos ao uso de distintas defasagens em testes de Granger-causalidade. Especificamente, a hipótese nula do teste ("Índice CRB não Granger-causa Nível de Atividade") é rejeitada ao nível de significância de $1 \%$ na ampla maioria dos casos.

A Tabela 9 contém testes de robustez na mesma linha dos testes anteriores, embora relacionados a um amplo conjunto de variáveis econômicas referentes ao estado. Nesse caso, também é possível notar que a maior parte dos resultados obtidos acima acaba sendo confirmada para números alternativos de defasagens. Significa que a grande maioria das variáveis consideradas sofre precedência temporal do índice $\mathrm{CRB}$, com exceções ocorrendo apenas no caso de horas pagas e pessoal ocupado na indústria, do índice de produção industrial do setor de alimentação e das vendas no varejo, resultados em consonância com aqueles reportados anteriormente para o Espírito Santo. 
Tabela 9

Robustez: testes de Granger-causalidade com números de defasagens alternativos (1, 2, 4 defasagens) para distintas variáveis econômicas, Espírito Santo

\begin{tabular}{l|c|c|c|c|c|c}
\hline \multirow{2}{*}{$\begin{array}{l}\text { H0: Índice CRB não Granger-causa Variável } \\
\text { Econômica }\end{array}$} & \multicolumn{3}{|c}{ Primeiras Diferenças } & \multicolumn{3}{c}{ Componentes Cíclicos } \\
\cline { 2 - 7 } & 1 & 2 & 4 & 1 & 2 & 4 \\
\hline Importações & $0,008^{* * *}$ & $0,000^{* * *}$ & $0,004^{* * *}$ & $0,000^{* * *}$ & $0,000^{* * *}$ & $0,003^{* *}$ \\
\hline Exportações & $0,000^{* * *}$ & $0,000^{* * *}$ & $0,000^{* * *}$ & $0,000^{* * *}$ & $0,000^{* * *}$ & $0,000^{* * *}$ \\
\hline Horas Pagas na Indústria & 0,154 & 0,466 & 0,359 & $0,017 * *$ & 0,187 & 0,476 \\
\hline Pessoal Ocupado na Indústria & 0,111 & 0,233 & 0,271 & $0,019 * *$ & 0,156 & 0,517 \\
\hline Produção Industrial - Geral & $0,000^{* * *}$ & $0,000^{* * *}$ & $0,000^{* * *}$ & 0,253 & $0,000^{* * *}$ & $0,000^{* * *}$ \\
\hline Produção Industrial - Alimentação & 0,624 & 0,564 & 0,682 & 0,256 & 0,517 & 0,598 \\
\hline Produção Industrial - Celulose & 0,309 & $0,064^{*}$ & $0,005^{* * *}$ & $0,050^{* *}$ & $0,000^{* * *}$ & $0,009^{* * *}$ \\
\hline Produção Industrial - Extrativista & $0,000^{* * *}$ & $0,000^{* * *}$ & $0,000^{* * *}$ & $0,013^{* *}$ & $0,000^{* * *}$ & $0,000^{* * *}$ \\
\hline Produção Industrial - Metalurgia & 0,106 & $0,002^{* * *}$ & $0,010^{* *}$ & 0,707 & $0,002^{* * *}$ & $0,008^{* * *}$ \\
\hline Produção Industrial - Minerais & $0,019 * *$ & $0,028^{* *}$ & 0,24 & $0,009 * * *$ & $0,044 * *$ & 0,176 \\
\hline Produção Industrial - Transformação & $0,029 * *$ & $0,001 * * *$ & $0,000^{* * *}$ & 0,608 & $0,000^{* * *}$ & $0,000^{* * *}$ \\
\hline Vendas Varejo & 0,664 & 0,865 & 0,584 & 0,259 & 0,701 & 0,490 \\
\hline
\end{tabular}

Notas: (a) Foram empregados números alternativos de defasagens (1, 2 e 4) nos testes de Granger-causalidade.

(b) $\mathrm{Na}$ tabela, são reportados os p-valores associados à hipótese nula do teste $\left(\mathrm{H}_{0}\right.$ : "Índice $\mathrm{CRB}$ não Granger-causa Variável Econômica").

(c) Os termos $(*),(* *)$ e $(* * *)$ denotam rejeição da hipótese nula do teste em níveis de significância de $10 \%, 5 \%$ e $1 \%$, respectivamente.

Fonte: Cálculos do autor, com base em dados do CRB e do IBGE. 
De acordo com os resultados reportados, pode-se notar que os padrões empíricos descritos anteriormente são robustos ao uso de distintos números de defasagens empregados nos testes.

\subsection{Uso de distintos índices de preços de commodities em testes de Granger- causalidade}

Um teste de robustez adicional que pode ser feito no presente contexto equivale à realização de testes de Granger-causalidade, envolvendo distintos índices de preços de commodities. No caso, a partir da utilização de índices de preços referentes a tipos específicos de commodities, buscou-se checar a ocorrência de um padrão de precedência temporal destes em relação ao nível de atividade.

A Tabela 10 contém os resultados desse teste de robustez. Para tanto, foram utilizados índices de preços de commodities oriundos do CRB e do FMI. Utilizaram-se tanto índices de preço de gorduras e metais provenientes do CRB, quanto índices de preços de produtos agrícolas, combustíveis e metais provenientes do FMI. Em consonância com a análise anterior, resultados são reportados para distintas transformações estacionárias dos dados (primeiras diferenças e componentes cíclicos), assim como números de defasagens alternativos (1,2 e 4).

Tabela 10

Robustez: testes de Granger-Causalidade, envolvendo distintos índices de preços de commodities, Brasil e Espírito Santo

\begin{tabular}{|c|c|c|c|c|c|c|c|}
\hline \multicolumn{3}{|c|}{ Commodities } & $\begin{array}{c}\text { CRB } \\
\text { Gorduras }\end{array}$ & $\begin{array}{l}\text { CRB } \\
\text { Metais }\end{array}$ & $\begin{array}{c}\text { FMI } \\
\text { Agrícolas }\end{array}$ & $\begin{array}{c}\text { FMI } \\
\text { Combustíveis }\end{array}$ & $\begin{array}{c}\text { FMI } \\
\text { Metais }\end{array}$ \\
\hline \multirow{6}{*}{$\begin{array}{c}\text { Produção } \\
\text { industrial } \\
\text { Espírito } \\
\text { Santo }\end{array}$} & \multirow{3}{*}{$\begin{array}{l}\text { Primeiras- } \\
\text { Diferenças }\end{array}$} & 1 & 0,991 & $0,002 * * *$ & 0,786 & 0,301 & 0,36 \\
\hline & & 2 & 0,934 & $0,010 * *$ & $0,051^{*}$ & $0,044 * *$ & 0,135 \\
\hline & & 4 & 0,537 & 0,171 & 0,353 & $0,000 * * *$ & 0,424 \\
\hline & \multirow{3}{*}{$\begin{array}{c}\text { Componentes } \\
\text { Cíclicos }\end{array}$} & 1 & 0,673 & $0,020 * *$ & 0,811 & 0,407 & 0,466 \\
\hline & & 2 & 0,835 & $0,013 * *$ & 0,271 & $0,005 * * *$ & 0,127 \\
\hline & & 4 & 0,408 & $0,062 *$ & 0,349 & $0,037 * *$ & 0,272 \\
\hline \multirow{6}{*}{$\begin{array}{c}\text { Produção } \\
\text { Industrial } \\
\text { Brasil }\end{array}$} & \multirow{3}{*}{$\begin{array}{l}\text { Primeiras- } \\
\text { Diferenças }\end{array}$} & 1 & 0,86 & $0,000 * * *$ & 0,287 & 0,497 & $0,013 * *$ \\
\hline & & 2 & 0,937 & $0,002 * * *$ & $0,033 * *$ & 0,346 & $0,008 * * *$ \\
\hline & & 4 & 0,653 & $0,064^{*}$ & $0,073^{*}$ & $0,027 * *$ & $0,0418^{* *}$ \\
\hline & \multirow{3}{*}{$\begin{array}{l}\text { Componentes } \\
\text { Cíclicos }\end{array}$} & 1 & 0,634 & $0,001 * * *$ & 0,137 & 0,755 & $0,057^{*}$ \\
\hline & & 2 & 0,697 & $0,010 * *$ & 0,026 & 0,441 & $0,004 * * *$ \\
\hline & & 4 & 0,857 & $0,039 * *$ & $0,016^{*}$ & 0,609 & $0,009 * * *$ \\
\hline
\end{tabular}

Notas: (a) Foram empregados números alternativos de defasagens (1, 2 e 4$)$ nos testes de Grangercausalidade.

(b) Na tabela, são reportados os p-valores associados à hipótese nula do teste $\left(\mathrm{H}_{0}\right.$ : "Índice de Preços de Commodities não Granger-causa Nível de Atividade").

(c) Os termos $\left(^{*}\right),(* *)$ e $(* * *)$ denotam rejeição da hipótese nula do teste aos níveis de significância de $10 \%, 5 \%$ e $1 \%$, respectivamente.

Fonte: Cálculos do autor, com base em dados do CRB, do IBGE e do FMI. 
Os resultados obtidos nesse caso demonstram que o padrão de precedência temporal dos preços de commodities em relação ao nível de atividade parece estar condicionado ao tipo de commodity considerada nos testes. Assim, nota-se que, no caso dos preços de gorduras, não há um padrão de precedência temporal dessa variável sobre o nível de atividade, qualquer que seja o número de defasagens considerado. Do mesmo modo, parece não haver um padrão claro no caso de produtos agrícolas. Por outro lado, os preços de commodities metálicas do CRB precedem temporalmente o nível de atividade, tanto no caso estadual quanto no nacional.

Dois resultados dignos de nota no presente contexto dizem respeito ao fato de que, enquanto os preços de combustíveis aparentam exercer um padrão de precedência temporal apenas sobre o nível de atividade do Espírito Santo, os preços de commodities metálicas do FMI exercem o mesmo efeito apenas sobre o nível de atividade do Brasil. Esses resultados, provavelmente, decorrem de diferenças nas estruturas produtivas do país e do estado, merecendo ser temas de investigações futuras.

\section{Conclusões e agenda de pesquisa futura}

Sendo um dos estados brasileiros com maior grau de abertura ao comércio exterior, o Espírito Santo encontra-se em uma posição em que possui maior exposição relativa a choques externos, especialmente, os relacionados a preços de commodities, devido a atual composição de sua pauta de exportações. Por conta disso, o principal objetivo do trabalho foi verificar, empiricamente, os efeitos de variações nos preços de commodities sobre o nível de atividade estadual a partir do emprego da metodologia VAR e de testes de Granger-causalidade na análise das séries temporais aqui consideradas.

Os principais resultados obtidos foram os seguintes:

i. Por conta de seu alto grau de abertura, o estado do Espírito Santo sente mais intensamente os impactos de choques nos preços de commodities do que o Brasil e demais estados;

ii. Preços de commodities, quando medidos a partir do índice CRB, exercem um padrão de precedência temporal sobre os níveis de atividade estadual e nacional;

iii. Padrão semelhante de precedência temporal também ocorre no caso de amplo conjunto de variáveis econômicas relacionadas ao estado do Espírito Santo; 
iv. Um choque positivo nos preços de commodities faz com que o nível de atividade estadual aumente inicialmente, sofrendo uma contração em seguida, para então apresentar um aumento permanente em relação a seu nível original;

v. Resultados de um exercício de decomposição da variância demonstram que, em média, os impactos quantitativos de choques nos preços de commodities são maiores no caso estadual do que no nacional (1,2 vezes maior).

Os resultados obtidos são robustos a diversas questões de especificação, tais como o uso de diferentes transformações estacionárias dos dados e de distintos números de defasagens empregados nos testes de Granger-causalidade. Por outro lado, vale notar que os resultados relacionados a testes de Granger-causalidade não são robustos ao uso de índices alternativos de preços de commodities. Uma possível explicação para esse resultado equivaleria ao fato de existirem significativas diferenças entre as estruturas produtivas do país e do estado.

Em termos de pesquisa futura, ficam três sugestões básicas. Em primeiro lugar, sugere-se a elaboração de estudos empíricos que empreguem bases de dados e/ou períodos amostrais distintos, não apenas para o caso estadual, mas também para as demais UFs como forma de checar a robustez de alguns dos principais resultados aqui descritos. Além disso, fica a sugestão de que sejam feitas investigações empíricas mais detalhadas relacionadas a diferenças existentes entre os padrões reportados para o estado e o país, que podem ser úteis no sentido de aumentar a compreensão da dinâmica econômica inerente a cada uma dessas unidades de análise.

Uma segunda estratégia de pesquisa equivale à construção de indicadores antecedentes de atividade econômica estadual a partir de preços de commodities, em moldes semelhantes a Bonelli, Bastos e Abreu (2009), por exemplo. Dados os resultados relacionados a testes de Granger-causalidade reportados anteriormente, preços de commodities parecem exercer um padrão de precedência temporal robusto em relação às flutuações do nível de atividade do estado.

Em terceiro lugar, sugere-se a formulação de modelos teóricos que possam adequar-se aos padrões empíricos aqui descritos, assim como gerar previsões úteis para fins de política econômica. A título de exemplo, a construção de um modelo de equilíbrio geral dinâmico com uma pequena economia aberta que sofresse choques em seus termos de troca (ou nos preços dos bens que exporta), conforme proposto por Mendoza (1991), poderia ser útil para o cálculo das respostas quantitativas daí advindas, assim como para a elaboração de previsões relacionadas a distintos cenários macroeconômicos.

Dada a forte influência dos preços de commodities sobre as flutuações do nível de atividade do estado do Espírito Santo, faz-se necessária uma melhor 
compreensão dos impactos quantitativos de variações dos preços no curto prazo. Espera-se que o presente trabalho possa contribuir como um primeiro passo nessa direção.

\section{Referências bibliográficas}

BANCO CENTRAL DO BRASIL (BACEN). Balanço de Pagamentos - Apresentação por Setores Institucionais, 24 abr. 2007. Disponível em: http://www.bcb.gov.br/ftp/infecon/BalPagSet_P.pdf. Acesso em: 23 fev. 2011.

BARTELSMAN, E. J.; DOMS, M. Understanding productivity: lessons from longitudinal microdata. Journal of Economic Literature, v. 38, n. 3, p.569-594, Sept. 2000.

BLANCHARD, O. J.; SIMON, J. The long and large decline in U.S. output volatility. Brookings Papers on Economic Activity, v. 1, n. 1, p. 135-164, 2001.

BONELLI, R.; BASTOS, E. K. X.; ABREU, P. C. A. Metodologia e sistema de cálculo do indicador do Produto Interno Bruto (PIB) em bases trimestrais para o estado do Espirito Santo. Vitória, ES: IJSN, set. 2009. 47p. (Texto para Discussão, n. 7). Disponível em: http://www.ijsn.es.gov.br/_databases/docstd/td-07.pdf. Acesso em: 14 dez. 2009.

BUENO, R. D. L. S. Econometria de séries temporais. Cengage Learning: São Paulo, 2008. 300p.

CANOVA, F. VAR models: specification, estimation, inference and forecasting. In: PESARAN, H.; WICKENS, M. Handbook of applied econometrics, v. 1. Brasil Blackwell, 1995. p. 73-137.

CONJUNTURA ECONÔMICA. Nova ferramenta para acompanhar os ciclos econômicos brasileiros. Conjuntura Econômica, v. 63, n. 6, p. 30-32, jun. 2009.

COMMODITY RESEARCH BUREAU (CRB). CRB Datacenter, 2010. Disponível em: http://www.crbtrader.com/datacenter.asp. Acesso em: 13 abr. 2010.

DICKEY, D. A.; FULLER, W. A. Likelihood ratio statistics for autoregressive time series with a unit root. Econometrica, v. 49, n. 4, p.1057-1073, 1981.

ENDERS, W. Applied econometric time series. John Wiley and Sons, 1995. 433p.

ENGLE, R. F.; GRANGER, C. W. J. Co-integration and error-correction: representation, estimation and testing. Econometrica, v. 55, n. 1, p. 251-276, 1987.

GRANGER, C. W. J. Investigating causal relations by econometric models and crossspectral methods. Econometrica, v. 37, n. 3, p. 424-438, 1969.

HODRICK, R.; PRESCOTT, E. C. Post-war U.S. business cycles: a descriptive empirical investigation. Journal of Money, Credit and Banking, v. 29, n. 1, p. 1-16, 1997. 
INSTITUTO BRASILEIRO DE GEOGRAFIA E ESTATÍSTICA (IBGE). Indicadores Conjunturais da Indústria - Produção. 2004. 260p. (Série Relatórios Metodológicos, v. 31).

INTERNATIONAL MONETARY FUND (IMF). IMF Primary Commodity Prices, 2010. Disponível em: http://www.imf.org/external/np/res/commod/index.aspx. Acesso em: 15 fev. 2010.

JACKS, D. S.; O'ROURKE, K. H.; WILLIAMSON, J. Commodity price volatility and world market integration since 1700. 2009. 36p. (NBER Working Paper, n. 14748). Disponível em: http://www.nber.org/papers/w14748. Acesso em: 14 jan. 2010.

KWIATKOWSKI, D.; PHILLIPS, P.C.B.; SCHMIDT, P.; SHIN, Y. Testing the null hypothesis of stationarity against the alternative of unit root. Journal of Econometrics, v. 54, n. 1, p. 159-178, 1992.

MACKINNON, J. G. Critical values for cointegration tests. In: ENGLE, R. F.; GRANGER, C. W. J. (Ed.). Long-run economic relationships: readings in cointegration. Oxford Univ., 1991.

MAGAlhães, M. A. Preços de commodities e nível de atividade no Espírito Santo: um estudo econométrico. Vitória, ES: IJSN, maio 2010. 37p. (Texto para Discussão, n. 13). Disponível em: http://www.ijsn.es.gov.br/attachments/542 ijsn td13.pdf. Acesso em: 18 jun. 2010.

; RIBEIRO, A. P. L. Fatos estilizados dos ciclos de negócios no estado do Espírito Santo: uma abordagem quantitativa. Revista Econômica do Nordeste, v. 42, n. 3, jul./set. 2011. A sair.

; TOSCANO, V. N. Grau de abertura da economia do estado do Espírito Santo no período $1^{\circ}$ trim./04 - 2 ${ }^{\circ}$ trim./09. Indicadores Econômicos FEE, v. 37, n. 4, 2009.

Abertura, concentração e volatilidade: uma análise dos efeitos da crise de 2007-2008 sobre o estado do Espírito Santo em 2009. Vitória, ES: IJSN, , maio 2010. 29p. Manuscrito.

; Concentração da pauta de exportações do Espírito Santo: uma análise empírica. Vitória, ES: IJSN, maio 2011. 26p. (Nota Técnica, n. 23). (Disponível em: http://www.ijsn.es.gov.br/attachments/956_ijsn_nt23.pdf. Acesso em: 15 jun. 2011.

MENDOZA, E. G. Real business cycles in a small open economy. American Economic Review, v. 81, n. 4, p. 797-818, Sept. 1991.

PANORAMA ECONÔMICO - Espírito Santo 2009. Vitória, ES: IJSN, vários números. Disponível em: http://www.ijsn.es.gov.br/follow.asp?urlframe=emdestaque/4592.asp. Acesso em: 22 mar. 2010.

PEREIRA, L. V. A contribuição das commodities às exportações. Conjuntura Econômica, v. 63 , n. 9 , p. $68-70$, set. 2009. 
PEREIRA, L. V.; MACIEL, D. S. O comércio exterior do estado do Espírito Santo. In: VESCOVI, A. P. V.; BONELLI, R. (Org.). Espirito Santo: instituições, desenvolvimento e inclusão social. Vitória, ES: IJSN, 2010. p. 95-137.

PHILliPS, P. C. B.; PERRON, P. Testing for a unit root in time series regression. Biometrika, v. 75, n. 3, p. 335-346, 1988.

PRATES, D. M. A alta recente dos preços das commodities. Revista de Economia Politica, v. 27, n. 3, p. 323-344, 2007.

; MARÇAL, E. F. O papel do ciclo de preços no desempenho recente das exportações brasileiras. Análise Econômica, v.49, p. 163-191, mar. 2008.

PREBISCH, R. The economic development of Latin America and its principal problems. New York: United Nations, 1950.

PUGA, F. Balança comercial brasileira: muito além das commodities. Visão do Desenvolvimento, BNDES, n. 54, 24 set. 2008. 8p. Disponível em: http://www.bndes.gov.br/SiteBNDES/export/sites/default/bndes_pt/Galerias/Arquivos/con hecimento/visao/visao 54.pdf. Acesso em: 23 nov. 2009.

SIMS, C. Money, income and causality. American Economic Review, v. 62, n. 3, p.540555, Sept. 1972.

. Macroeconomics and reality. Econometrica, v. 48, n. 1, p. 1-48, Jan. 1980.

SOUZA, N. J. Abertura comercial e crescimento dos estados brasileiros, 1991/2000. Teoria e Evidência Econômica, v. 11, n. 21, p. 41-61, nov. 2003.

STOCK, J. H.; WATSON, M. W. Business cycle fluctuations in U.S. macroeconomic time series. In: TAYLOR, J.; WOODFORD, M. (Ed.). Handbook of macroeconomics. North-Holland, 2000. p. 3-64.

n. 1, p. 101-116, fall 2001 .

Vector autoregressions. Journal of Economic Perspectives, v. 15,

THURMAN, W. N.; FISHER, M. E. Chickens, eggs, and causality, or which came first? American Journal of Agricultural Economics, v. 70, n. 2, p. 237-238, May 1988. 


\section{Apêndice A}

Estatíticas descritivas das variáveis utilizadas na análise

A Tabela A1 abaixo contém as estatísticas descritivas das principais variáveis analisadas neste trabalho.

Tabela A1

Estatísticas descritivas das principais variáveis usadas na análise

\begin{tabular}{|c|c|c|c|c|c|c|}
\hline & & Média & Mediana & $\begin{array}{l}\text { Desvio- } \\
\text { Padrão }\end{array}$ & Máximo & Mínimo \\
\hline \multirow{13}{*}{$\begin{array}{l}\text { Índices de } \\
\text { Produção } \\
\text { Industrial }\end{array}$} & $\mathrm{BR}$ & 97,61 & 95,21 & 15,00 & 131,02 & 71,22 \\
\hline & AM & 122,32 & 125,39 & 15,24 & 153,82 & 86,39 \\
\hline & PA & 127,67 & 128,64 & 18,10 & 157,64 & 91,45 \\
\hline & $\mathrm{CE}$ & 99,40 & 98,44 & 13,93 & 129,75 & 68,97 \\
\hline & $\mathrm{PE}$ & 112,66 & 111,52 & 10,24 & 146,56 & 92,18 \\
\hline & BA & 101,96 & 100,85 & 12,32 & 128,44 & 63,89 \\
\hline & MG & 99,21 & 96,66 & 17,01 & 141,18 & 70,76 \\
\hline & RJ & 86,22 & 85,50 & 16,79 & 111,99 & 49,25 \\
\hline & SP & 102,06 & 98,88 & 14,71 & 138,44 & 75,16 \\
\hline & PR & 103,23 & 100,48 & 16,11 & 140,09 & 65,71 \\
\hline & $\mathrm{SC}$ & 98,15 & 99,85 & 10,21 & 115,57 & 72,75 \\
\hline & $\mathrm{RS}$ & 94,17 & 96,66 & 11,43 & 117,03 & 61,61 \\
\hline & GO & 117,76 & 118,36 & 12,05 & 146,02 & 93,86 \\
\hline \multirow{7}{*}{$\begin{array}{c}\text { Índices de } \\
\text { Produção } \\
\text { Industrial - } \\
\text { ES }\end{array}$} & Geral & 93,0 & 88,8 & 24,49 & 156,14 & 53,24 \\
\hline & Extrativa & 85,4 & 67,66 & 39,69 & 190,23 & 38,1 \\
\hline & Transformação & 96,1 & 96,07 & 19,49 & 143,17 & 54,33 \\
\hline & Alimentação & 120,1 & 117,59 & 23,89 & 245,73 & 65,12 \\
\hline & Celulose & 90,6 & 79,28 & 32,05 & 150,85 & 22,06 \\
\hline & Minerais & 91,7 & 97,36 & 18,42 & 128,88 & 46,95 \\
\hline & Metalurgia & 88,5 & 89,51 & 24,88 & 156,5 & 49,84 \\
\hline \multicolumn{2}{|l|}{ Exportações } & $291.287,79$ & $215.016,00$ & $199.880,24$ & $1.205 .638,00$ & $20.555,00$ \\
\hline \multicolumn{2}{|l|}{ Importações } & $255.228,57$ & $219.533,00$ & $179.118,56$ & $846.577,00$ & $32.379,00$ \\
\hline \multicolumn{2}{|c|}{ Horas Pagas na Indústria } & 95,06 & 95,51 & 2,92 & 100,57 & 87,94 \\
\hline \multicolumn{2}{|c|}{ Pessoal Ocupado na Indústria } & 94,38 & 94,65 & 3,29 & 101,16 & 85,89 \\
\hline \multicolumn{2}{|c|}{ Vendas no Varejo } & 128,73 & 120,64 & 28,47 & 217,43 & 88,30 \\
\hline \multicolumn{2}{|l|}{ Índice CRB } & 295,06 & 248,45 & 100,99 & 595,98 & 182,95 \\
\hline \multicolumn{2}{|c|}{ Índice CRB - Gorduras } & 256,44 & 250,87 & 78,85 & 535,78 & 151,07 \\
\hline \multicolumn{2}{|c|}{ Índice CRB - Metais } & 390,53 & 273,83 & 224,89 & 950,91 & 170,37 \\
\hline \multicolumn{2}{|c|}{ Índice CRB - Agrícolas } & 93,56 & 97,34 & 18,00 & 132,35 & 56,92 \\
\hline
\end{tabular}

Notas: (a) Todas as variáveis da tabela estão expressas em índices, com exceção das exportações e importações, expressas em US\$ milhões.

(b) Variáveis que exibiam padrões sazonais foram previamente dessazonalizadas a partir do método ARIMA X-12.

Fonte: Cálculos do autor, com base em dados do CRB e do IBGE. 